\title{
Voluntary Disclosure and Earnings Management
}

\begin{abstract}
Discretion pervades the accounting rules. Proponents argue that allowing discretion enables managers to incorporate more information in their disclosures, while opponents believe that managers can abuse discretion and engage in earnings management at the expense of shareholders. We explicitly model accounting discretion and earnings management in a disclosure setting motivated by Shin (1994). We use this setting to study the interaction between management's voluntary disclosure and the subsequent mandatory disclosure of valuerelevant information. We show that, in equilibrium, allowing the manager to have some discretion over the mandatory financial reports may enhance the informativeness of the moretimely voluntary disclosure. However, allowing too much discretion for earnings management may result in less informative voluntary disclosure. Thus there may be a hidden benefit of granting some (but not too much) discretion in firms' mandatory financial statements.
\end{abstract}




\section{Voluntary Disclosure and Earnings Management}

\section{Introduction}

We investigate analytically the interaction between a firm's voluntary disclosure and the subsequent mandatory disclosure of value-relevant information and explore the effect of accounting discretion allowed in the mandatory disclosure on the informativeness of the voluntary disclosure. We utilize a setting where a firm's manager has private information about the firm's value that cannot be directly and verifiably communicated to outsiders and introduce a new way of modeling accounting discretion. We show that, in equilibrium, allowing the manager some discretion over the mandatory financial reports may enhance the informativeness of the more timely voluntary disclosure, a counterintuitive result. But we also show that too much discretion can render the voluntary disclosure less informative. Thus from the perspective of maximizing the informativeness of voluntary disclosure, allowing the manager to manage the reported earnings can be beneficial, but there is a maximal amount of discretion that should be tolerated, consistent with the discretion embedded in the generally accepted accounting principles (GAAP).

Discretion pervades the accounting rules, as reflected by the wide use of estimates in measuring various accounting items (e.g., bad debt expense, contingent liabilities), choice of accounting methods for the same economic transactions and assets and liabilities (e.g., straightline vs. accelerated depreciation, cost model vs. revaluation model for long-lived assets), etc. Proponents argue that such discretion has various benefits. For example, Dutta and Gigler (2002), from a contracting perspective, demonstrate that earnings management reduces the cost of eliciting truthful voluntary disclosures from managers. Dye (1988) shows that agency considerations result in an equilibrium demand for earnings management because compensation contracts designed to motivate managerial effort become more efficient, while Trueman and Titman (1988) show that a firm has an incentive to smooth reported earnings when debtholders use these reported numbers to estimate the volatility of its earnings. In a related paper, Fishman and Hagerty (1990) show in a persuasion game setting that allowing some reporting discretion may or may not result in improved informativeness of disclosure, depending on which of the two equilibria is chosen. In the papers mentioned above, discretion gives managers the option of misreporting what they observe, with arguably desirable results. 
In a more recent paper, Drymiotes and Hemmer (2013) investigate the role of accruals in earnings quality from both valuation and stewardship perspectives. They find that neither an "aggressive" nor a "conservative" accrual strategy is optimal. The accrual strategy in their setting generates biased earnings numbers ex ante, which differs from the ex post earnings management that we focus on.

Critics complain that discretion enables managers to engage in "earnings management," that is, to use the discretion provided by GAAP to manipulate accounting data and report income numbers that reflect managers' objectives rather than the true economic income numbers of firms (Schipper 1989). The Securities and Exchange Commission (SEC) has publicly stated that earnings management is one of the greatest evils plaguing the accounting profession (Levitt 1998). This concern has been reinforced by such high-profile accounting scandals as those at Enron and WorldCom. Empirical studies provide strong evidence that firms manage earnings to meet or beat earnings targets, such as last years' earnings or consensus forecasts of earnings provided by financial analysts and firms themselves (see, for example, Burgstahler and Dichev 1997; Degeorge et al. 1999; Bartov et. al. 2002). ${ }^{1}$ This line of research argues that earnings management decreases investor confidence and undermines the credibility of accounting reports. To date, there has been a lack of systematic studies on the benefit-cost tradeoff of allowing some degree of discretion in accounting rules in the presence of both voluntary and mandatory disclosures. ${ }^{2}$

The empirical literature indicates that earnings management is strongly related to earnings forecasts (e.g., Degeorge et al. 1999) and that voluntary disclosure and mandatory financial reports complement each other because the primarily backward-looking and less timely mandatory reports encourage managers to disclose voluntarily (and credibly) their forward-looking and timely private information (Ball et al. 2012). However, there is little research so far that simultaneously examines managers' voluntary earnings forecasts and the

\footnotetext{
${ }^{1}$ Other examples include Carter et al. (2007) and Roychowdhury (2006). Carter et al. (2007) document that firms facing financial reporting concerns, such as meeting or beating earnings benchmarks and avoiding violation of debt covenants, overused stock options to compensate their employees before the enactment of SFAS 123R, which required the expensing of stock options. Roychowdhury (2006) provides evidence consistent with managers manipulating real activities (e.g., offering price discounts to temporarily increase sales or overproducing to report lower cost of goods sold) to avoid reporting annual losses or to meet annual analyst forecasts.

${ }^{2}$ Dye and Verrecchia (1995), in a principal-agent setting, study the effect of allowing managerial discretion in reporting current period expenses. They show this can be desirable sometimes and undesirable other times. Fischer and Verrecchia (2000), Sankar and Subramanyam (2001), and Ewert and Wagenhofer $(2005,2013)$ study the effect of accounting discretion on the properties of mandatory accounting reports in market settings.
} 
subsequent management of the mandatorily announced earnings. The voluntary and mandatory disclosures made by managers, as well as the equilibrium price response to them, are endogenously determined. Thus if there are relationships among them, they must be shown to hold in equilibrium. In fact, Ball et al. (2012) strongly assert that the economic roles of (audited) mandatory and (unaudited) voluntary disclosures cannot be evaluated separately. Beyer et al. (2010) also emphasize the need for models to examine voluntary and mandatory disclosures simultaneously. ${ }^{3}$ We respond to such calls and propose an analytical model that jointly determines the equilibrium voluntary and mandatory disclosures. We also propose a new approach of modeling accounting discretion and study how discretion affects the properties of disclosures.

Our model is motivated by the model of Shin (1994). Early voluntary disclosure literature generally assumes that the manager is either uninformed or perfectly informed (e.g., Grossman 1981; Dye 1985; Jung and Kwon 1988). This stream of work demonstrates that, in equilibrium, the manager either discloses the entire truth or keeps silent. Shin (1994) studies a setting in which the manager simultaneously learns both good and bad news and shows that the optimal disclosure strategy is the "sanitization strategy," that is, disclosing only good news (the lower bound of the firm's value that can be justified by his signals) and withholding all bad news (the upper bound of the firm's value that can be justified by his signals). Shin (1994) introduces imprecision to the manager's information set; that is, the manager learns a possible set (or a range) of values that the underlying "true" earnings will fall in, and as a result, his voluntary disclosure can be interpreted as either a range or a point disclosure and does not have to be the entire truth. This feature is empirically appealing, and our setting allows us to preserve this interpretation of the manager's voluntary disclosure. We build our model using the private information structure similar to Shin's (1994), but we relax the assumption that the true earnings is verifiable, thus allowing the manager to manage the reported earnings when necessary.

Specifically, the manager of a firm observes privately some information regarding the firm's "true" earnings (i.e., the possible values that the "true" earnings might take and the

\footnotetext{
3 “" $[\mathrm{We}]$ encourage researchers to investigate the interplay between management forecasts and mandatory disclosures in general ... [It] would be useful to combine analyses of voluntary disclosures with mandatory disclosure to investigate ... the extent to which mandatory disclosure requirements affect ... the amount of voluntary disclosures" (Beyer et al. 2010, 314).
} 
probability that each of these values will be realized). The nature of the true earnings and the private information that the manager receives depend on his ability, with the manager of higher ability being more likely to generate higher true earnings and potentially more likely to observe more precise private information about true earnings. The manager is not aware of his ability level before working for the firm and may (partially) learn his ability level when private signals are realized. The manager has the option to make a voluntary disclosure of the expected earnings based on his private information, before his mandatory report of the firms' earnings after learning the realization of the true earnings. The firm is then sold to a new investor based on the voluntary and mandatory disclosures. The manager chooses both the voluntary and mandatory disclosure strategies to maximize a weighted average of the selling price of the firm and the market's perception of his ability. We assume that the true earnings can be observed only by the manager and is never observed by the outside investor, at least during the manager's horizon. What the outside investor observes are the voluntary disclosure and the reported earnings, which can be managed by the manager. We assume that, given the discretion that the manager has over the accounting report, he incurs no cost for managing the reported earnings, but earnings management may not be successful (i.e., the manager fails to make the reported earnings to reach the prior set target). In such cases, the manager will incur an (endogenous) penalty in that the market will perceive him to be more likely of low ability. We interpret the ex-ante probability of successful earnings management as the discretion granted by GAAP to the manager. In other words, for a given amount of earnings management, higher probability of successful earnings management indicates more discretion for the manager. ${ }^{4}$

We show that, relaxing the maintained assumption in the prior disclosure literature that the manager cannot manage the reported earnings in a setting of a joint determination of voluntary and mandatory disclosures can generate interesting insights. Specifically, allowing a limited degree of discretion to the manager to manage the mandatorily reported earnings can lead to the manager incorporating more private information in his voluntary disclosure. The intuition underlying this result is as follows. If the manager is given no discretion so that any attempt to manage earnings is blocked, he is then "forced" to disclose the lower bound of his

\footnotetext{
${ }^{4}$ The term "discretion" refers to practices allowed under the accounting rules that can potentially affect reported earnings, e.g., straight-line versus accelerated depreciation methods, not practices that are considered outright fraud, e.g., forged bank accounts.
} 
observed information set, regardless of his knowledge about the probability distribution of the true earnings on this set because of the penalty arising from the market's perception that the manager is of low ability when the voluntary and mandatory disclosures are inconsistent. For example, suppose that, before the realization of the true earnings, the manager knows that the probability distribution of the true earnings is skewed to the right so that the true earnings number is likely to be high. However, the manager cannot rule out the possibility that earnings may turn out to be low, although he knows this is unlikely. Because the manager cannot afford to voluntarily disclose a number that has any chance of being short of the realization, despite it being extremely unlikely, he can only make the disclosure that earnings will be above the lower bound of the support of the earnings distribution that he has privately learned. Thus much of what the manager knows (i.e., the distribution) cannot be communicated.

Now, suppose that the realization of the true earnings is not mechanically revealed but is reported by the manager and the report is subject to management with some probability of success. Given the feasibility of managing the subsequent mandatory reports, the earlier forecast of earnings provided by the manager would depend crucially upon the probability distribution of the true earnings the manager privately knows. If this probability distribution is sufficiently skewed to the right, the manager would communicate a higher earnings forecast to inflate the price of the firm. He would do this knowing that the chance of the true earnings falling below the forecast would be small and therefore the chances of managing the reported earnings and incurring a penalty when the earnings management is unsuccessful would also be small. Thus allowing the manager some discretion to manage the reported earnings can lead to a (counterintuitive) result: the earlier voluntary forecast of earnings reveals more of the manager's private information - the probability distribution of the earnings.

This intuition, however, does not hold at the other extreme. When the manager is granted too much discretion, he can almost always manage the reported earnings to a target level with no reference to the true earnings. As a result, he will always voluntarily disclose that the earnings number is high, regardless of his private information. The voluntary disclosure will then have no information content. Thus an intermediate degree of discretion allows for the maximum informativeness of voluntary disclosure. ${ }^{5}$

\footnotetext{
${ }^{5}$ Beyer et al. (2010) document that a great majority of the firm-provided financial information is conveyed through managers' voluntary disclosure. Thus improving the informativeness of voluntary disclosure is potentially
} 
Our paper makes several contributions to the literature. First, we uncover a hidden benefit to earnings management, thus providing some rationale for the allowance of discretion imbedded in GAAP. In this sense, our paper adds to the literature on the desirability of some tolerance for earnings management, although we derive this intuition in a market setting as opposed to an agency setting, as in Arya et al. (1998), Dutta and Gigler (2002) and Arya et al. (2003). Sankar and Subramanyam (2001) consider a two-period model and focus on mandatory disclosure with the possibility that part of the earnings management has to be reversed in the second period, whereas we focus on a single period and show that discretion results in the manager incorporating private information in voluntary disclosure without such reversal. Stocken and Verrecchia (2004), and Ewert and Wagenhafer (2013) introduce nonfinancial information privately owned by a manager that can at most be partially captured by the firm's accounting system. The former show that a privately informed manager may endogenously choose an imprecise accounting system and the efficiency of this choice depends on the usefulness of accounting information. The latter show that, under certain conditions, less discretion allowed in reporting earnings reduces earnings quality. Both papers focus on mandatory disclosure, while we consider both mandatory and voluntary disclosures. Finally, Fishman and Hagerty (1990) study the effect of discretion on the property of disclosure. However, in their model, there is only one managerial disclosure decision, and the discretion allowed is directly over that single disclosure. The manager also is required to disclose a signal from a pre-specified subset of available signals (which makes the disclosure more of a mandatory one in nature). Thus the disclosure itself must be truthful. The authors are therefore silent about the interaction between the two distinct forms of disclosure that are central to accounting. Our contribution is to demonstrate the desirability of granting the manager discretion over his mandatory disclosure as it enhances the informativeness of the more timely voluntary disclosure.

Second, we jointly study voluntary and mandatory disclosures, while focusing on the interaction between those two types of disclosures. Our result shows that investigating the

important for resource allocation in capital markets. We do not directly model investment. Rather we focus on how the interaction of mandatory and voluntary disclosures affects the informativeness of voluntary disclosure, a first and necessary step leading to the real implications of such an interaction. Also although allowing discretion may improve the informativeness of voluntary disclosure, it decreases the informativeness of mandatory disclosure. We do not examine the overall informativeness of the two disclosures. So long as the informativeness of voluntary disclosure is sufficiently important, allowing some degree of discretion can be beneficial. 
desirability of accounting discretion in the sole framework of earnings management and whether it impairs the integrity of mandatory disclosures can be misleading, because prohibiting the management of mandatory reports can have some unintended consequences for the voluntary disclosures. We propose that studies of the benefits or costs of earnings management should jointly consider the tradeoff between those two types of disclosures.

Einhorn and Ziv (2012) examine a double-tier disclosure decision and explore the interactions between the decision to disclose and the bias in the disclosure if it is made. The two dimensions of disclosures are assumed to be made simultaneously in their model, which ignores the potential disciplinary effect of subsequent mandatory disclosure has on the voluntary disclosure that we focus on. ${ }^{6}$ Kwon et al. (2009) explicitly model such an effect. However, in their model, mandatory disclosure cannot be managed. Several other papers maintain the assumption that mandatory disclosure cannot be managed or management (if allowed) of mandatory disclosure may be detected and penalized and demonstrate that the credibility of voluntary disclosure can be sustained (Sansing 1992; Stocken 2000; Lundholm 2003; Korn 2004). Beyer (2009) also jointly studies managers' optimal voluntary and mandatory disclosure strategies in a setting where the capital market is ignorant of both the mean and the variance of firms' underlying cash flows. However, her focus is on the properties of capital market responses, while ours is on the properties of managers' disclosures and, in particular, the relationship between mandatory and voluntary disclosures. Other related studies include Einhorn (2005), Bagnoli and Watts (2007), and Beyer and Guttman (2012), where voluntary disclosures are required to be truthful. Stocken (2013) provides a synthesized review of the theoretical literature on managers' strategic voluntary disclosure as the scope of discretion retained by managers varies from zero to infinity. A closely related paper is Boisits (2013), who studies the interplay between the two forms of disclosures by restricting to a constant bias mandatory reporting strategy and imposing two exogenous costs related to the disclosures to the model: 1) cost as a function of the difference between voluntary and mandatory disclosures and 2) cost as a function of the bias in mandatory disclosure. We endogenously derive the cost of

\footnotetext{
${ }^{6}$ We thank Phil Stocken for pointing this out.
} 
discrepancy between the voluntary and mandatory disclosures, ${ }^{7}$ and we impose no constraint on the form of mandatory disclosure.

By investigating the interaction between mandatory and voluntary disclosures, we also add to the literature on the economic role of accounting disclosures. In this regard, we take the same stand as Gigler and Hemmer (1998) and Gigler and Jiang (2015). Their studies emphasize the "confirmatory role" of mandatory accounting reports: by providing backward-looking information, they confirm the credibility of firms' more timely voluntary disclosures of forward-looking information. This view is empirically supported by Ball et al. (2012) and is strongly advocated by Ball et al. (2012) and Beyer et al. (2010). Our paper further shows that, even though limiting managers' discretion over financial reporting strengthens the "confirmatory role" of the mandatory reports, overly restricting managers' reporting behavior can lead to decreased informativeness of the voluntary disclosures. This is new in the literature.

Prior accounting studies on voluntary disclosure assume that any managerial disclosure can be costlessly and immediately verified by external parties but that a claim of ignorance cannot be verified. They demonstrate that, in equilibrium, the manager either discloses the entire truth or only discloses if the earnings news is sufficiently good (e.g., Grossman 1981; Verrecchia 1983; Dye 1985; Jung and Kwon 1988; Shin 1994). These studies show that voluntary disclosures are themselves managed, but they do not investigate the strategic interaction between voluntary disclosures and the mandatory disclosures that follow, because they assume that voluntary disclosures can be verified by the subsequent mandatory disclosure and that the mandatory disclosure cannot be managed. We relax this assumption and show that introducing such an important institutional feature of accounting generates interesting novel insights.

Third, we introduce a new way of modelling accounting discretion. The traditional earnings management literature assumes that earnings management is costly and the cost is commonly modeled as the (squared) distance between the true earnings and the reported earnings multiplied by a multiplier where the multiplier captures the notion of accounting discretion or enforcement of accounting rules (e.g., Fischer and Verrecchia 2000; Ewert and

\footnotetext{
${ }^{7}$ Most of the studies assume an exogenous cost if voluntary disclosure differs from the mandatory disclosure. Notable exceptions are Stocken (2000) and Lundholm (2003), who endogenize the cost in a repeated game setting. Beyer and Guttman (2012) introduce (endogenous) real costs to discipline the voluntary disclosure.
} 
Wagenhofer 2005; Beyer 2009). Our setting allows us to break down the earnings management cost as traditionally modeled into two components: the ex ante assessed probability that the earnings management may not succeed and the ex post cost (endogenously imposed by the market) that the manager may incur if the mandatorily reported accounting number falls below the voluntarily disclosed earnings number. We interpret the first component as the discretion granted by GAAP to the manager over financial reporting. In other words, for a given amount of earnings management, higher probability of successful earnings management indicates that more discretion is allowed to the manager. We believe such a characterization of accounting discretion better captures the institutional features of GAAP and also that distinguishing between these two components of the cost associated with earnings management helps to better understand the role of accounting discretion in the interaction between voluntary and mandatory disclosures.

Finally, our paper also provides some novel — and potentially testable-empirical implications regarding the relationship between earnings management and voluntary disclosure. The implication that the discretion embedded in the accounting rules could be positively associated with the price informativeness of voluntary disclosure has, to the best of our knowledge, not been tested.

The rest of the paper is organized as follows. Section 2 outlines the model setup. Section 3 defines and derives the equilibrium disclosure strategy and market response of the model. Section 4 discusses potential extensions of the baseline model and some empirical implications, and Section 5 concludes. The appendix contains all the proofs.

\section{The Model}

We consider a pure exchange economy. There is a risk-neutral manager who runs the firm, and a risk-neutral investor who owns one share of the firm. For exogenous reasons (for example, liquidity needs), the investor needs to sell, to a new risk-neutral investor, the share before consuming the true income of the firm. Disclosure thus plays a role in determining the selling price. There are two states of nature, denoted by $H$ and $L$, respectively. The firm is endowed with a project that generates underlying unmanaged true earnings of $x_{i}$ in state $i$, where $i=H$ or $L$. Without loss of generality, we assume that $x_{H}>x_{L}$, that is, state $H$ is 
considered more favorable than state $L$. The prior probabilities of the firm being in states $H$ and $L$ are denoted as $p_{H}$ and $p_{L}\left(=1-p_{H}\right)$ respectively. The manager can potentially privately observe a signal, $\tilde{\sigma}$, that is perfectly informative of the true earnings in that the signal $\tilde{\sigma}$ maps from the state space to the set $\{0,1\}$ that satisfies

$\sigma(j)= \begin{cases}0 & \text { if } j \in\{L\} \\ 1 & \text { if } j \in\{H\}\end{cases}$

The probability of observing $\tilde{\sigma}$ depends on the manager's ability to be specified below. When the manager does not observe $\tilde{\sigma}$, we assume that he observes a noisy signal $\tilde{s} \in\{h, l\}$ that is informative of the underlying state in the following manner:

$p(s=h \mid i=H)=p(s=l \mid i=L)=q \in\left(\frac{1}{2}, 1\right)$.

Note that equation (1) is a binary version of the signal structure in Shin (1994). When the manager observes $\tilde{\sigma}$, he knows the underlying state perfectly. When the manager does not learn $\tilde{\sigma}$, he still possesses more information, albeit noisy, about the underlying state. We further assume that the manager cannot credibly convey $\tilde{\sigma}$ and $\tilde{s}$ to the public directly due to their nonverifiable nature. Other than the manager's observed signal ( $\tilde{\sigma}$ or $\tilde{s})$ and, later on, the realized true earnings, everything else is common knowledge. Our introduction of the noisy signals observed by the manager is a parsimonious way of introducing one of the key features of our model: even if the manager does not know the underlying state precisely, he may still possess more information than outside investors about what the true earnings will be.

We assume there are three levels of managerial ability $a_{1}(q) \leq a_{2}<a_{3}$. The manager does not know his ability before he operates the firm and he may (partially) learn of his type from observing $\sigma$ or $s$. The manager of the highest ability, $a_{3}$, generates $x_{H}$, whereas a lower type manager $\left(a_{2}\right.$ or $\left.a_{1}(q)\right)$ generates $x_{L}$. Furthermore, while manager of $a_{2}$ observes $\sigma=0$ so that he is sure that $x=x_{L}$, the manager of the lowest ability, $a_{1}(q)$, only observes signal $\tilde{s}$. The highest ability manager observes either $\sigma=1$ or $\tilde{s}$. These assumptions capture the idea that managerial ability consists of two parts: the ability to generate (1) high earnings and (2) important internal information useful for decision-making. The manager who generates low earnings but can identify it earlier is conceived to have better ability than the manager who 
generates low earnings but fails to identify it timely due to low quality internal information. We further assume that $\lim _{q \rightarrow 1} a_{1}(q)=a_{2}$, that is, when $s$ becomes perfectly informative about the underlying state, the manager can always identify the true earnings earlier. We suppress the dependence of $a_{1}$ on $q$ in subsequent analysis as our results hold for any $q \in\left(\frac{1}{2}, 1\right){ }^{8}$

Conditional on $\tilde{x}$, the probability that the manager observes $\tilde{\sigma}$ is $\theta$. Thus the prior probability of manager's ability being $a_{1}, a_{2}$, and $a_{3}$ is $p_{L}(1-\theta), p_{L} \theta$, and $p_{H}$, respectively.

After observing the private signal, the manager has the option to issue a voluntary disclosure, $D$. Because the state of nature is binary, there are two possible voluntary disclosures: $D_{L} \equiv\left\{x \geq x_{L}\right\}$, interpreted in equilibrium as earnings is at least $x_{L}$ as in Shin (1994), and $D_{H} \equiv\left\{x \geq x_{H}\right\}$, interpreted as earnings is at least $x_{H}$ (which, in our case, is equivalent to $\left.x=x_{H}\right) .{ }^{9}$ The true earnings number is then realized and is privately observed by the manager. The manager then issues a mandatory disclosure, $R \in\left\{R_{H}, R_{L}\right\}$, where $R_{H} \equiv\{x=$ $\left.x_{H}\right\}$ and $R_{L} \equiv\left\{x=x_{L}\right\}$. We depart from the prior literature by assuming that true earnings cannot be observed or verified by anybody, at least during the manager's horizon, which is not unreasonable because (1) accounting involves accruals and deferrals that make the underlying earnings generating process not so transparent, and (2) the manager's horizon is generally shorter than that of a firm. Thus we explicitly allow the manager to be able to manage the mandatory disclosure with some probability of success. For example, if the manager voluntarily discloses $D_{H}$, while the true earnings turns out to be $x_{L}$, the manager then has two options: he can choose not to manage the mandatory disclosure and announce $R=R_{L}$, or he can choose to engage in earnings management that can with some probability increase the reported earnings to $R_{H}$. We assume that the probability of successfully managing earnings up from $R_{L}$ to $R_{H}$ is a constant $\delta \in[0,1)$. We use $m(D, x, R) \in\{0,1\}$ to denote the manager's earnings management strategies with $m(D, x, R)=0(1)$ denoting no earnings management (earnings management). We also assume that the manager can always manage earnings down with probability 1 . The

\footnotetext{
${ }^{8}$ Alternatively, we can assume that the manager chooses $q$ subject to a cost of $c(q)$ and that his objective is to maximize firm's selling price plus his perceived ability minus $c(q)$. So long as $\lim _{q \rightarrow 1} c(q)=+\infty$, we will have an interior solution of $q$, and our main results remain qualitatively unchanged.

${ }^{9}$ The manager can also choose to keep silent. In our model remaining silent is equivalent to disclosing $D_{L}$. As in Shin (1994), it can also be verified that the manager will never find it optimal to disclose only the upper bound of the earnings, that is, earnings is at most $x_{H}$ or $x_{L}$.
} 
manager chooses $D, R$, and $m$ to maximize $P(D, R ; m)+\lambda E[a \mid D, R ; m]$, that is, the weighted sum of the selling price of the firm and his perceived ability by the capital market, where $\lambda>0$ represents the relative weight on the perceived ability, given the manager's disclosures. ${ }^{10}$ One way to interpret the objective function is that the first term represents current compensation and the second one captures future compensation determined by perceived managerial ability.

The timeline of the model is summarized as follows.

Date 0: Nature chooses the manager's type. The underlying state $i \in\{H, L\}$ and the realizations of $\tilde{\sigma}$ and (possibly) $\tilde{s}$ are then determined based on manager's type and equations (1) and (2).

Date 1: The manager (possibly) makes a voluntary disclosure, $D$, regarding the firms' future true earnings. The firm's true earnings number is realized and observed by the manager. The manager then issues a mandatory disclosure of the firm's earnings, $R$, that is subject to potential management, $m$, by the manager with some success probability. The firm is then sold to a new investor. The manager chooses $D, R$, and $m$ to maximize $P(D, R ; m)+\lambda E[a \mid D, R ; m]$.

Date 3: The new investor consumes firm's true earnings.

It is worth elaborating on how we model earnings management in the presence of discretion granted by GAAP. Our formulation relates to but differs somewhat from the literature's usual assumption of an upfront earnings management cost (e.g., Fischer and Stocken 2004; Guttman et al. 2006; Beyer 2009). Departing from the formulation of direct upfront earnings management cost that summarizes into a single term both the constraint imposed by the accounting rules and the expected adverse consequences, our formulation allows for a focus on the first component, that is, the constraint imposed by the accounting rules. This is modelled by the success probability $\delta$ of managing reported earnings upward. This success probability represents the discretion allowed in the accounting rules in the sense that more discretion increases the probability of successful earnings management (see, e.g., Chen et al. 2007; Gao 2013; and Laux and Stocken 2012). To illustrate this point, consider the example of revenue recognition. Suppose that the accounting rule stipulates revenue is only recognized when cash is

\footnotetext{
${ }^{10}$ Throughout the paper, we use the upper case letter $P$ to represent the price response and the lower case letter $p$ to represent probability.
} 
received. Since the amount of revenue recognized must equal the amount of cash received, without altering the timing and amount of the flow of cash, the probability that the manager can manage revenue up is zero, corresponding to an accounting rule with zero discretion. On the other hand, suppose that the accounting rule allows the manager to estimate the amount of cash to be received as the recognized amount of revenue. The manager can then increase his estimate to recognize a higher revenue number without managing the real cash flow, which corresponds to an accounting rule with some discretion. However, because earnings numbers reflect both operational uncertainties and reporting constraints imposed by accounting rules, the manager may not always be able to manage the reported earnings to achieve his target. Thus we assume that he has a success probability of less than one and that this probability is an increasing function of the amount of discretion allowed in the accounting rules. We model the second component as the perceived ability of the manager after both the voluntary and mandatory disclosures. This perceived ability (endogenously) captures the ex-post consequences borne by the manager when the mandatory disclosure is inconsistent with the preceding voluntary disclosure. We believe the separation of the two components is particularly relevant in our setting and allows us to isolate the effect of the ex ante discretion allowed in accounting rules on the manager's disclosure strategies from the interference of the ex post consequences.

In the next section, we solve for the equilibrium (pure strategy) voluntary and mandatory disclosure strategies of the manager and illustrate our central message: allowing some degree of discretion in the mandatory disclosure can enhance the informativeness of the voluntary disclosure, but allowing too much discretion undercuts the informativeness of the voluntary disclosure. Appendix A summarizes the notations used in this paper.

\section{Managers' Optimal Voluntary and Mandatory Disclosure Strategies}

Denote $\Omega$ as manager's information set before making voluntary disclosure. From the discussion above the manager observes either $\tilde{\sigma}$ or $\tilde{s}$. Let $E[$.$] and p($.$) be the expectation and$ probability operators respectively. The Bayesian-Nash equilibrium of this game is defined as follows. 
Definition: A Bayesian-Nash equilibrium contains the manager's voluntary disclosure strategy, $D(\Omega)$, mandatory disclosure strategy, $R(D, x)$, earnings management strategy $m(D, x, R) \in$ $\{0,1\}$, and the market's pricing rule at the mandatory disclosure date, $P(D, R ; m)$, such that:

(i) $\quad D(\Omega), R(D, x)$, and $m(D, x, R)$ maximize the manager's expected payoff, $E[\widehat{P}(D, R ; m)]+\lambda E[a \mid D, R ; m]$, where $\hat{P}(D, R ; m)$ is the manager's conjecture about the investors' pricing rule in response to the voluntary and mandatory disclosures and the manager's earnings management strategy;

(ii) The risk-neutral investor sets up $P(D, \hat{R}(D, x) ; \widehat{m}(D, x, R))=$ $E(\tilde{x} \mid D, \hat{R}(D, x) ; \widehat{m}(D, x, R))$ after observing $D$, where $\hat{R}$ and $\widehat{m}$ are the investor's conjectures about the manager's mandatory disclosure and earnings management strategy, respectively;

(iii) $\quad P(D, R ; m)=\hat{P}(D, R ; m), \hat{R}(D, x)=R(D, x)$, and $\widehat{m}(D, x, R)=m(D, x, R)$, i.e., in equilibrium, the conjectured pricing rule and mandatory disclosure and earnings management strategies are consistent with the actual pricing rules and mandatory disclosure and earnings management strategies;

(iv) The conditional distribution of $R$ on $x$ is consistent with the manager's mandatory disclosure strategy, $R(D, x)$, and his earnings management strategy $m(D, x, R)$, i.e., $p\left(R=R_{H} \mid R\left(D, x_{H}\right)=R_{H}, m\right)=1$ and $p\left(R=R_{L} \mid R\left(D, x_{L}\right)=R_{L}, m\right)=1 \forall D, m ;$ and, $p\left(R=R_{H} \mid R\left(D, x_{L}\right)=R_{H}, m=1\right)=\delta$ and $p\left(R=R_{L} \mid R\left(D, x_{L}\right)=R_{H}, m=1\right)=$ $1-\delta \forall D$.

Before continuing our discussion of equilibrium, we would like to remind the readers of one feature of our model. Since manager's payoff is determined by the market's perception of managerial ability, we would have multiple equilibria in the following sense: given any equilibrium voluntary disclosure strategy, one can switch the strategies and get the same equilibrium with a corresponding switch of market's beliefs. For example, suppose the following is an equilibrium strategy: the manager discloses $D_{H}$ when observing $\sigma=1$ and discloses $D_{L}$ otherwise, and market believes that $D_{H}$ comes from a manager who observes $\sigma=$ 1 and that $D_{L}$ comes from a manager who observes anything other than $\sigma=1$. Then the following is also an equilibrium: the manager discloses $D_{L}$ when observing $\sigma=1$ and discloses 
$D_{H}$ otherwise, and market believes that $D_{L}$ comes from a manager who observes $\sigma=1$ and that $D_{H}$ comes from a manager who observes anything other than $\sigma=1$. Those two equilibria are essentially the same in terms of the price informativeness of disclosure and managerial payoff. This multiplicity stems from the fact that market can assign $D_{H}$ to be associated with better news than $D_{L}$ or vice versa. To remove this type of multiplicity, we only focus on equilibria where $D_{H}$ is associated with no worse news than $D_{L}$, denoted as $P\left(D_{H}\right) \geq P\left(D_{L}\right)$. Our subsequent discussions will be based on this simplification. Proposition 1 characterizes all pure strategy equilibria when no discretion is allowed.

Proposition 1: When no discretion is allowed over mandatory disclosure, i.e., $\delta=0$, there are two pure strategy equilibria: (1) the "uninformative equilibrium" in which the manager chooses the same voluntary disclosure strategy regardless of the signal; and 2) the "sanitization equilibrium" in which the manager chooses to disclose $D_{H}$ whenever $\sigma=1$ and to disclose $D_{L}$ otherwise. However, neither of the equilibria survives the intuitive criterion (Cho and Kreps 1987).

\section{Proof: All proofs are in Appendix B.}

Proposition 1 says that there are two pure strategy equilibria when $\delta=0$. In the uninformative equilibrium, manager of all types makes the same voluntary disclosure, and the investor ignores the manager's disclosure (so the manager is indifferent between disclosing $D_{H}$ or disclosing $D_{L}$, regardless of his private information). This makes voluntary disclosure uninformative. The "sanitization equilibrium" follows from Shin (1994) and refers to a situation where the manager discloses the lower bound of his private information. For example, the manager discloses $D_{L}$ so long as he knows that true earnings can be $x_{L}$ for a nonzero probability. In our setting, as long as the manager does not observe $\sigma=1$, he cannot rule out the case that true earnings could be $x_{L}$. This is true even when he observes $s=h$, which can indicate that true earnings are very likely to be $x_{H}$ if $q$ is sufficiently large. Thus the sanitization equilibrium in our setting refers to the equilibrium where the manager discloses $D_{H}$ only when $\sigma=1$ and $D_{L}$ otherwise. The intuition for such a strategy to be an equilibrium strategy is as follows. Investor's perception of managerial ability is based on $D$ and $R$. Since the manager of higher ability tends to issue $D$ and $R$ that are more likely to be consistent with each other (i.e., 
$R=R_{H}$ when $D=D_{H}$, and $R=R_{L}$ when $D=D_{L}$ ), the investor will perceive the inconsistency between $D$ and $R$ as from a manager of the lowest ability (i.e., $a=a_{1}$ ), resulting in an (endogenous) penalty to the manager. The manager whose private information indicates a low probability of true earnings being $x_{H}$ will want to disclose $D_{L}$ to avoid being conceived as the lowest ability manager. Thus sanitization strategy can be supported in equilibrium.

However, both pure strategy equilibria can be eliminated by the intuitive criterion proposed by Cho and Kreps (1987) (hereafter referred to as the intuitive criterion). In particular, while the sanitization equilibrium can be sustained by proper out-of-equilibrium beliefs as illustrated in Shin (1994) due to the exogenous nature of the penalty for mismatches between voluntary and mandatory disclosures, it does not survive the intuitive criterion in our setting. The reason is that the penalty in our setting is endogenous and stems from the market's perception of managerial ability, which depends on the market's beliefs, including out-ofequilibrium beliefs. When the manager uses the sanitization strategy, $\left\{D_{H}, R_{L}\right\}$ is on the offequilibrium path. Since $R_{L}$ indicates that managerial ability is either $a_{1}$ or $a_{2}, E\left[a \mid D_{H}, R_{L}\right]$ will be a probability-weighted average of $a_{1}$ and $a_{2}$. The manager who observes $\sigma=0$ knows that his ability is $a_{2}$. He thus has an incentive to send an off-equilibrium message $D_{H}$ and increase $E\left[a \mid D_{H}, R_{L}\right]$ to $a_{2}$. This implies that no out-of-equilibrium beliefs will support the sanitization equilibrium while at the same time satisfying the intuitive criterion. Similarly, the completely uninformative equilibrium can be eliminated by the intuitive criterion, as the manager who observes $\sigma=1$ has an incentive to deviate and increase market's perceived ability of him.

Nevertheless, we still use the sanitization equilibrium as a benchmark in our future discussion of price informativeness of voluntary disclosure because this is the equilibrium that yields a higher price informativeness when no discretion is allowed. Thus, if we could show that the equilibrium in the presence of discretion generates more informative voluntary disclosure than the sanitization equilibrium, then allowing discretion increases the informativeness of voluntary disclosure unambiguously. Note that, in the sanitization equilibrium, the manager chooses $D_{L}$ whenever $\sigma$ is not 1 , even when he has favorable private information (i.e., observing $s=h$ ). As we will see below, this results in potentially large information loss in his voluntary disclosure when the private signal is sufficiently informative, that is, when $q$ is sufficiently large. 
We now examine the case where discretion is allowed, that is, $\delta>0$. Since the manager can manage earnings, there are more strategies available to him and potentially more possible pure strategy equilibria. Proposition 2 shows that, among the four possible pure strategy equilibria, three can be eliminated by suitable selection criteria. This leaves us with only one pure strategy equilibrium, denoted as "separation with management equilibrium," which will be our focus for subsequent discussions.

Proposition 2: Denote $k \equiv \frac{x_{H}-x_{L}+\lambda\left(a_{3}-a_{2}\right)}{\lambda\left(a_{2}-a_{1}\right)}$. When discretion is allowed, there are four possible pure strategy equilibria.

1. There always exists an equilibrium, denoted as "uninformative equilibrium" in which the manager always discloses $D_{H}$ or $D_{L}$, regardless of his private signal, and engages in upward earnings management when $x=x_{L}$.

2. There may be an equilibrium, denoted as "sanitization with management equilibrium" in which the manager discloses $D_{H}$ when he observes $\sigma=1$ and discloses $D_{L}$ otherwise. The manager always engages in upward earnings management when $x=x_{L}$. This equilibrium is possible if $(k+1) \frac{\delta p_{L}}{(1-\theta) p_{H}+\delta p_{L}}<$ $\frac{(1-\delta) p_{L}(1-q)}{\delta p_{L}(1-q)+p_{H} q}$, or equivalently, $\delta$ is smaller than some threshold $\delta_{s m}^{*} \in(0,1)$.

3. There may be an equilibrium, denoted as "separation with management equilibrium" in which the manager discloses $D_{H}$ when he observes $\sigma=1$ or $s=h$, and discloses $D_{L}$ otherwise. The manager always engages in upward earnings management when $x=x_{L}$. This equilibrium is possible if

$$
\begin{aligned}
& \frac{(1-\delta)\left(1-p_{H}\right)(1-q)}{\delta\left(1-p_{H}\right)(1-q)+p_{H} q} \frac{\theta}{q(1-\theta)+\theta}< \\
& \frac{k \delta p_{L} p_{H}(2 q-1+2 \theta(1-q))+\delta p_{L}(1-\theta)\left(-\delta p_{L}(1-q) \theta+p_{H}(q(2-\theta)-(1-\theta))\right)}{\left(p_{H}(q+\theta)-p_{H} q \theta+\delta p_{L}(1-q)(1-\theta)\right)\left((1-q)(1-\theta) p_{H}+\delta p_{L}(q+\theta-q \theta)\right)} \\
& <\frac{(1-\delta)\left(1-p_{H}\right) q}{\delta\left(1-p_{H}\right) q+p_{H}(1-q)} \frac{\theta}{q(1-\theta)+\theta} .
\end{aligned}
$$


i) When $p_{H}>\frac{\theta(1-q)}{\theta+(1-\theta)(2 q-1)}$, there always exists a $\delta^{*} \in(0,1)$ s.t. for $\delta=\delta^{*}$, such an equilibrium exists;

ii) When $p_{H} \geq \frac{1}{2}$ and $k$ is sufficiently large, there exist $\underline{\delta}$ and $\bar{\delta}$ where $0<\underline{\delta}<\bar{\delta}<1$ such that this equilibrium exists if and only if $\delta \in(\underline{\delta}, \bar{\delta})$; and,

iii) When $p_{H}$ is sufficiently small, such an equilibrium does not exist.

4. There may be an equilibrium, denoted as "reverse sanitization with management equilibrium" in which the manager discloses $D_{L}$ when he observes $\sigma=0$ and discloses $D_{H}$ otherwise. The manager always engages in upward earnings management when $x=x_{L}$. This equilibrium is possible if $\frac{p_{H}(1-q)}{p_{H}(1-q)+q\left(1-p_{H}\right)}+\frac{q\left(1-p_{H}\right)}{p_{H}(1-q)+q\left(1-p_{H}\right)} \delta>\frac{\delta p_{L}(1-\theta)}{p_{H}}+\frac{1}{k+1}>\delta$.

Among the four possible equilibria, the first, second, and fourth can be eliminated with suitable equilibrium selection criteria.

Proposition 2 states that there will be pervasive earnings management in all pure strategy equilibria. When reporting $R_{L}$, the investor knows that true earnings must be $x_{L}$ and the manager's ability is at most $a_{2}$. When reporting $R_{H}$, the investor knows that true earnings can be $x_{H}$ and the manager's ability can be $a_{3}$. The proof of Proposition 2 shows that $E[\tilde{x}+$ $\left.\lambda a \mid D, R_{H}\right] \geq E\left[\tilde{x}+\lambda a \mid D, R_{L}\right]$, regardless of $D$. Since earnings management has no upfront cost, the manager will always want to manage earnings up when true earnings number is $x_{L}$.

Proposition 2 also shows that the uninformative equilibrium and the sanitization equilibrium in the absence of discretion over mandatory disclosure are still preserved when discretion is allowed, although the sanitization equilibrium is only possible for sufficiently small $\delta$ (i.e., low levels of discretion). The uninformative equilibrium always exists because it is always possible for the investor to ignore the manager's voluntary disclosure. The sustainability of the sanitization equilibrium, on the other hand, relies on the endogenous penalty arising from lower perceived managerial ability when $D_{H}$ is followed by $R_{L}$. When $\delta$ becomes larger (i.e., more discretion is granted), such an event becomes less likely as the manager can manage earnings up with a higher probability of success. The expected penalty 
thus becomes smaller, making the sanitization equilibrium eventually not sustainable. To see this more clearly, the condition in Proposition 2 that ensures the existence of the sanitization with management equilibrium comes from $\left(1-\left(1-p_{H h}\right)(1-\delta)\right)\left(U_{H H}-U_{L H}\right)<(1-$ $\left.p_{H h}\right)(1-\delta)\left(U_{L L}-U_{H L}\right)$, where $p_{H i}$ denotes the probability of true earnings being $x_{H}$ when manager observes $s=i \in\{h, l\}$, and $U_{t v} \equiv E\left[\tilde{x}+\lambda a \mid D_{t}, R_{v}\right]$ is the manager's payoff at the voluntary disclosure $D_{t}$ and mandatory disclosure $R_{v}$, for $t, v=H, L$. The right hand side term thus represents the loss for the manager who observes $s=h$ and discloses $D_{H}$ (relative to $D_{L}$ ) when mandatory disclosure turns out to be $R_{L}$, which occurs with probability $\left(1-p_{H h}\right)(1-$ $\delta$ ), that is, when true earnings is $x_{L}$ and earnings management is unsuccessful. The left-side term represents the gain for the manager who observes $s=h$ and discloses $D_{H}$ (relative to $D_{L}$ ) when mandatory disclosure turns out to be $R_{H}$, which occurs with probability $1-(1-$ $\left.p_{H h}\right)(1-\delta)$. When the gain is smaller than the loss, the manager who observes $s=h$ has no incentive to disclose $D_{H}$. This implies that the manager who observes $s=l$ or $\sigma=0$ has no incentive to disclose $D_{H}$ either since his gain from disclosing $D_{H}$ is even more dominated by his loss from disclosing $D_{H}$. The left hand side can be shown to be increasing in $\delta$ whereas the right hand side is decreasing in $\delta$. Therefore this equilibrium is sustainable only when $\delta$ is sufficiently small.

The opportunity to manage earnings also introduces two more pure strategy equilibria that are otherwise not available: the "reverse sanitization with management equilibrium" and the "separation with management equilibrium." The term "reverse sanitization" refers to disclosing the upper bound of the manager's information set, as opposed to the lower bound in the sanitization equilibrium. Recall that in the sanitization equilibrium, the manager discloses $D_{H}$ only when he is sure that the true earnings number is $x_{H}$. In the reverse sanitization equilibrium, the manager discloses $D_{L}$ only when he is sure that the true earnings number is $x_{L}$. Thus disclosing $D_{H}$ can result in a penalty when it is followed by $R_{L}$. However, allowing discretion increases the attractiveness of disclosing $D_{H}$ in two ways. First, the manager can reduce the incidence of the penalty through successful upward earnings management when $x=x_{L}$. Second, for the manager who observes $\sigma=0$ and follows the reverse sanitization strategy, $E\left[\tilde{x}+\lambda a \mid D_{L}, R\right]=x_{L}+\lambda a_{2}$ for $\forall R$. This is also the payoff of a manager who observes $s$ (but not $\sigma$ ) and deviates from the reverse sanitization strategy by switching from $D_{H}$ 
to $D_{L}$. The expected cost and benefit of this deviation is twofold: the expected true earnings is reduced from a weighted average of $x_{L}$ and $x_{H}$ to $x_{L}$ (a net cost), and the perceived ability is changed from a weighted average of $a_{1}$ and $a_{3}$ to $a_{2}$ (a net cost or benefit). The conditions specified in Proposition 2 ensure that the expected benefit exceeds the expected cost, thus rendering disclosing $D_{H}$ the optimal strategy when $\sigma=0$ is not observed. ${ }^{11}$ To see this more clearly, note that the conditions in Proposition 2 come from $\left(1-\left(1-p_{H l}\right)(1-\delta)\right)\left(U_{H H}-\right.$ $\left.U_{L H}\right)>\left(1-p_{H l}\right)(1-\delta)\left(U_{L L}-U_{H L}\right)$ and $\delta\left(U_{H H}-U_{L H}\right)<(1-\delta)\left(U_{L L}-U_{H L}\right)$. Applying similar reasoning as that in the discussion of sanitization with management equilibrium, the first inequality guarantees that the expected benefit of disclosing $D_{H}$ exceeds the expected cost when the manager observes $s=l$. This ensures the optimality of disclosing $D_{H}$ for the manager who observes $s=h$ or $\sigma=1$ since his expected benefit from disclosing $D_{H}$ is even more dominant relative to his expected cost. The second inequality says that the expected benefit of disclosing $D_{H}$ is smaller than the cost when the manager observes $\sigma=0$. Thus the "reverse sanitization with management equilibrium" is sustained.

In the "separation with management equilibrium," the manager again can incur a penalty by disclosing $D_{H}$ when he is not sure that the true earnings number is $x_{H}$. Similarly, allowing discretion in mandatory disclosure reduces the likelihood of such a penalty and increases the attractiveness of disclosing $D_{H}$. When $\delta$ is neither too large nor too small, the manager who observes $s=h$ will find the reduction in the expected penalty sufficiently large to prefer disclosing $D_{H}$; however, for the manager who observes $s=l$ or $\sigma=0$, this reduction is too small so he still prefers to disclose $D_{L}$. This intuition is reflected in the two conditions in Proposition 2, which can be rewritten as $\left(1-\left(1-p_{H l}\right)(1-\delta)\right)\left(U_{H H}-U_{L H}\right)<(1-$ $\left.p_{H l}\right)(1-\delta)\left(U_{L L}-U_{H L}\right)$ and $\left(1-\left(1-p_{H h}\right)(1-\delta)\right)\left(U_{H H}-U_{L H}\right)>\left(1-p_{H h}\right)(1-$ $\delta)\left(U_{L L}-U_{H L}\right)$. The first inequality ensures that the manager who observes $s=l$ finds it too costly to disclose $D_{H}$, whereas the second inequality ensures that the manager who observes $s=h$ finds it preferable to disclose $D_{H}$. This generates a separation in voluntary disclosure in

\footnotetext{
${ }^{11}$ Note that it may seem plausible that under certain parameters, the equilibrium condition of the reverse sanitization with management equilibrium can be supported when no discretion is allowed (i.e., $\delta=0$ ). However, this is due to a discontinuity nature in investor's beliefs. When $\delta=0, R_{H}\left(R_{L}\right)$ implies that true earnings must be $x_{H}\left(x_{L}\right)$, so $E\left[a \mid D, R_{H}\right]=a_{3}$ for $D=D_{H}, D_{L} ; E\left[a \mid D_{L}, R_{L}\right]=a_{2}$; and $E\left[a \mid D_{H}, R_{L}\right]=a_{1}$. While when $\delta>0$, under the reverse sanitization strategy, $E\left[a \mid D_{H}, R_{H}\right]$ is a weighted average of $a_{1}$ and $a_{3}$.
} 
the sense that the manager discloses $D_{H}\left(D_{L}\right)$ when he has relatively good (bad) private information. Note that this equilibrium requires $p_{H}$ to be not too small. The reason is that, when seeing $D_{H}$ and $R_{H}$, the investor will assign some probability to the inference that this disclosure comes from the manager observing $s=h$. When $p_{H}$ is sufficiently low, the ex ante probability of true earnings being $x_{H}$ is very low. Thus the investor conjectures that any signal other than $\sigma=1$ is highly likely generated from $x_{L}$. This implies that the inferred probability that the manager is of the lowest ability given $D_{H}$ and $R_{H}$ or $p\left(a_{1} \mid D_{H}, R_{H}\right)$ is so high that $E\left[a \mid D_{H}, R_{H}\right]<E\left[a \mid D_{L}, R_{H}\right]$ and $E\left[\tilde{x}+\lambda a \mid D_{H}, R_{H}\right]<E\left[\tilde{x}+\lambda a \mid D_{L}, R_{H}\right]$, making the separation strategy not optimal.

Proposition 2 also shows that all equilibria other than the separation with management equilibrium can be eliminated by suitable equilibrium selection criterion. The intuition for eliminating the uninformative equilibrium and the sanitization with management equilibrium is the same as when no reporting discretion is allowed. The reverse sanitization with management equilibrium can be eliminated because it relies on the manager who observes $\sigma=0$ being indifferent between managing the reported earnings up and reporting truthfully. Hence, this equilibrium is vulnerable to a small perturbation of the payoffs of the persuasion game. We thus focus on the separation with management equilibrium for our subsequent analysis of the price informativeness of voluntary disclosures.

Proposition 2 reiterates the spirit of Shin (1994) in a subtle way. In Shin (1994), investors are rationally skeptical. So in valuing the firm, they weigh more (less) heavily the low (high) values implied by a voluntary disclosure. Such skepticism comes from the manager's incentive to strategically suppress unfavorable information about the states; that is, the manager suppresses information indicating that the earnings number is smaller than the biggest number inferred from his private information and only discloses that the earnings number is no smaller than the smallest number his information can possibly justify (i.e., the sanitization strategy). ${ }^{12}$ Therefore the degree of skepticism is an increasing function of the probability that the manager

\footnotetext{
${ }^{12}$ For example, given that the true earnings takes a value of $\{1,2,3,4\}$, if the manager's private information indicates that the earnings will actually be either 2 or 3 , he will disclose that the earnings is (at least) 2 but suppress the information that the earnings is at most 3 . Investors, observing a forecast of (at least) 2, can only infer that the earnings falls into one of the following: $\{2\},\{2,3\},\{2,3,4\},\{3\},\{3,4\}$, and, $\{4\}$. However, a forecast of (at least) 4 can only mean that the earnings number is in fact $\{4\}$.
} 
is informed, captured by the probability that each signal can be observed or $\theta$. In our setting, however, investors' skepticism comes from two sources: the manager's incentive to suppress bad news in his voluntary disclosure and the effect of the manager's potential upward earnings management to match his mandatory disclosure to his prior voluntary disclosure. When the success probability $\delta$ is low (i.e., a low level of discretion), the first source is the impetus, and our result mimics that of Shin. As $\delta$ increases, the second source gets stronger, and the sanitization strategy starts to fail to hold in equilibrium, resulting in a less obvious effect of $\theta$ on the degree of skepticism. On the other hand, the increase in $\delta$ makes the investor less skeptical about the low voluntary disclosures, and more about the higher ones, a result that is opposite to Shin (1994), where the investor is more skeptical when the voluntary disclosure is low and, at the extreme, takes literally the highest voluntary disclosure. In our case, the investor takes literally the lowest voluntary disclosure but is extremely skeptical about the highest voluntary disclosure in the reverse sanitization with management equilibrium.

Since the separation with management equilibrium identified in Proposition 2 incorporates more of the manager's private information than the sanitization equilibrium identified in Proposition 1, one would expect the informativeness of the voluntary disclosures in the former equilibrium to dominate that in the latter equilibrium when manager's private information is sufficiently precise. The next proposition shows that this intuition indeed holds. Note that we measure informativeness as the mean squared error of the price response to the fundamentals (i.e., the realized true earnings, $x$ ). The higher the mean squared error, the lower the informativeness of the voluntary disclosure (Gao 2008; Chen et al. 2012).

\section{Proposition 3}

When $p_{H} \geq \frac{1+\theta}{4 \theta}$, the voluntary disclosure is always more informative when some degree of discretion over the mandatory disclosure is allowed. When $p_{H}<\frac{1+\theta}{4 \theta}$, there exists a $q^{*} \in\left(\frac{1}{2}, 1\right)$ so that for $q>q^{*}$, the price informativeness of the voluntary disclosure is higher when some degree of discretion is allowed.

Proposition 3 thus implies that some degree of discretion is desirable in the sense of improving the informativeness of the voluntary disclosure. In other words, granting the 
manager some discretion over what he can report in his mandatory disclosure would enable him to convey to the market more of his private information, that is, his knowledge of the distribution of the true earnings. For example, when $q$ is large, the manager who observes $s=$ $h$ infers a sufficiently optimistic distribution of the earnings (i.e., skewed to the larger value) from his private signal. He can then make a higher earnings forecast, and in the case that the low earnings is realized (an low likelihood event), he will be able to potentially cover himself by using the granted discretion to manage earnings upward so that the reported earnings will not fall short of the forecast if earnings management is successful. Investors anticipate the manager's behavior and rationally interpret the manager's disclosure as conveying more than just the lower bound of his private information and price the firm accordingly, resulting in more information impounded in stock prices.

Note that Proposition 3 requires $q$ to be sufficiently high (i.e., private signal to be sufficiently informative) when $p_{H}$ is low. The intuition is as follows. When $p_{H}$ is low, the project is ex ante very likely to generate low earnings. Thus precise information regarding when the project would generate high earnings becomes very valuable. Since sanitization equilibrium exhibits perfectly informative good news disclosure, the noisy private information the manager incorporates into the voluntary disclosure has to be sufficiently precise for the separation disclosure to be more informative. When $p_{H}$ is high, however, precise information regarding when the project would generate low earnings becomes highly valuable, implying sanitization equilibrium is not very informative. Therefore incorporating any informative private information into the voluntary disclosure increases its informativeness.

Recall from Proposition 2 that the separation with management equilibrium requires the discretion allowed in mandatory disclosure, $\delta$, to be in the intermediate range, i.e., $\delta$ cannot be too large. This is intuitive, as giving the manager too much discretion would prompt him to ignore his private information and always disclose the highest value. He will then attempt to manage earnings up to the forecasted level whenever the realized earnings fall short. Consistent with this disclosure strategy, investors will choose to ignore the manager's disclosure completely, and thus no information other than the prior is priced. In this case, imposing some constraints on earnings management will make the manager with (highly) pessimistic information refrain from issuing unduly optimistic voluntary disclosure, again improving the 
information content of the voluntary disclosure. Hence, from the perspective of the informativeness of the voluntary disclosure, in its interaction with the mandatory disclosure, there exists a desirable level of discretion to be granted to the manager, a topic that has not been studied extensively. ${ }^{13}$

Previously, we mentioned that giving the manager the option to manage reported earnings might lead him to exercise this option for his own benefit. However, it is exactly this self-interested earnings management that sometimes enables the manager to incorporate more private information in his voluntary disclosure. Thus (opportunistic) earnings management can have a hidden benefit of improving the informativeness of the more timely voluntary disclosure, a message that we try to convey. Beyer et al. (2010) document that approximately $66 \%$ of the accounting-based information that investors use is provided by firms' voluntary disclosures, while mandatory disclosures account for less than $12 \%$. Therefore voluntary disclosure has become a major (and dominant) source of financial information that the capital market relies upon, and the informativeness of voluntary disclosure is thus an important efficiency metric. We believe the message that earnings management may help to improve the informativeness of voluntary disclosure has significant policy implications. To the best of our knowledge, this paper is one of the few analytical papers to provide justification for allowing managers some discretion in financial reporting in the context of the interaction between mandatory and voluntary disclosures with mandatory disclosure being used to discipline the more timely voluntary disclosure.

\section{Discussions and Empirical Implications}

We now discuss the effect of relaxing some of the modelling assumptions on our results.

First, for analytical tractability, we assume binary states of true underlying earnings, but we expect our results to hold qualitatively for a more general $N$-state model as in Shin (1994). The reason is that the intuition underlying the results of the binary states setting does not seem to alter in any significant way. So long as the market penalizes the manager in the form of

\footnotetext{
${ }^{13}$ Dye and Sridhar (2008) investigate the optimal level of discretion in a setting where accounting standards generate network externalities. They focus on mandatory financial statements. We do not address the issue of optimal level of disclosure as we only focus on the effect of discretion on the informativeness of voluntary disclosure.
} 
lower perceived managerial abilities for any mismatches between voluntary disclosure and the subsequent mandatory disclosure, in the absence of accounting discretion, the manager finds the sanitization strategy to be optimal to avoid such a penalty. As a result, he incorporates no private information into his voluntary disclosure. But with some degree of discretion over the mandatory disclosure and sufficiently precise private information, the manager with sufficiently optimistic private information finds that the likelihood of the subsequent (managed) mandatory disclosure falling short of a higher voluntary disclosure than the one that is warranted by the sanitization strategy is sufficiently low. Thus the benefit from forecasting a higher number (in terms of both a higher expected earnings number and a higher perceived ability) outweighs the expected penalty. Consequently, more private information is incorporated into the voluntary disclosure, making it more price informative.

Secondly, we assume that, when $x=x_{H}$, the manager's ability has no effect on whether $\sigma$ or $s$ will be observed. Again this assumption is for analytical tractability. We can modify the model to include four managerial ability levels with the manager observing $\sigma=1$ to have ability $a_{4}$, which is larger than $a_{3}$, now defined as the ability of the manager with $x=x_{H}$ observing $s$ but not $\sigma$. This modification increases the benefit of the manager who does not observe $\sigma$ and discloses $D_{H}$, as he may now be perceived as a manager with ability $a_{4}$. So long as the potential benefit, $a_{4}-a_{3}$ is sufficiently smaller than $a_{2}-a_{1}$, that is, the cost associated with disclosing $D_{H}$ followed by $R_{L}$, our main results remain unchanged. The intuition is that, when the manager does not observe $\sigma$, he is not entirely sure whether the true earnings will be low or high. The expected damage of his perceived ability from disclosing $D_{H}$ followed by $R_{L}$ when $x=x_{L}$ is too high compared to the expected damage from disclosing $D_{L}$ followed by $R_{H}$ when $x=x_{H}$. Thus, in the absence of discretion, the sanitization strategy is optimal. However, when some degree of discretion is allowed, separation with management strategy becomes optimal because the manager can manage earnings upward to lower such expected damage even when $x=x_{L}$.

The results of this paper offer insights into some empirical findings and yield additional empirical implications that could be tested. 
First, in an attempt to investigate whether accounting discretion is explained by managerial opportunism or efficient contracting, Bowen et al. (2008) provide empirical evidence that shareholders benefit from earnings management resulting from the latitude allowed by GAAP. They conjecture that this might be due to managers incorporating private information into accounting reports to signal competence or future performance. Our model suggests that the discretion imbedded in GAAP enables managers to convey more private information about firm performance and managerial ability through more timely voluntary disclosure.

Second, we show that some degree of earnings management can result in a more informative voluntary disclosure, despite a decreased (or "more skeptical") price response to the (high) voluntary disclosure. We are not aware of any empirical papers that directly test this hypothesis. ${ }^{14}$ Rogers and Stocken (2005) document that managers' willingness to bias their forecasts decreases with the market's ability to detect misrepresentation and that investors' response to management forecasts is consistent with their ability to identify predictable forecast biases in the management forecasts. This result comports with our story in the sense that investors are more skeptical toward management forecasts that are perceived to be inflated.

Most of the literature that explores the relationship between voluntary and mandatory disclosures focuses on the relationships between certain attributes of voluntary earnings forecasts and reported earnings. Kasznik (1999) hypothesizes and finds that managers make income-increasing accounting decisions when earnings would otherwise be below management forecasts on the premise that earnings forecast errors impose costs on managers (such as investors' perception of their (in)ability to anticipate changes in the economic environment), but he finds no evidence that underestimated earnings are associated with income-decreasing discretionary accruals. We confirm the findings in Kasznik (1999) that managers use earnings management to avoid disagreement between their voluntary and mandatory disclosures. However, our results go beyond showing a relationship between voluntary and mandatory disclosures. We further demonstrate that, under certain conditions, there exists a positive

\footnotetext{
${ }^{14}$ One possible exception is Kim (2012). He finds that managers with more accounting flexibility choose to issue more specific earnings forecasts before their firms' seasoned equity offerings. However, he also finds that forecasts are more optimistic, which may or may not increase price informativeness, and his setting is restricted to firms that issue seasoned equities.
} 
relationship between the degree of discretion allowed in managing reported earnings and the price informativeness of earnings forecasts.

Francis et al. (2008) find that firms with high-quality earnings have more expansive voluntary disclosure, while Hui, Matsunaga, and Morse (2009) document that more conservative accounting leads to fewer management forecasts. Our model implies that one possible explanation of these seemingly contradictory results is that the empirical proxies for the underlying constructs (e.g., conservatism and earnings quality) could have differential implications for managers' reporting discretion. Specifically, to the extent that more conservatism implies less discretion, our model implies that the sanitization equilibrium will be more likely to occur under more conservative accounting. This is consistent with the results of Hui et al. (2009), as the sanitization equilibrium is associated with a higher likelihood of disclosing $D_{L}$ or, equivalently, remaining silent in our model.

Third, Proposition 3 provides conditions where some degree of discretion will result in unambiguously more informative voluntary disclosures. Specifically, when $p_{H}$ is sufficiently

high, any voluntary disclosure that incorporates some of the manager's private information will be more informative. Thus the first prediction that more discretion increases the informativeness of voluntary disclosure will be stronger for firms with more profitable projects. In addition, Proposition 3 also predicts that when $q$ is sufficiently large, that is, the noisy private information is more precise, more discretion will always increase the informativeness of voluntary disclosure, regardless of the value of $p_{H}$. Since in our model $q$ represents the information asymmetry between managers and outside shareholders, we would also expect the first prediction to be stronger for firms with more information asymmetry between managers and outside shareholders.

\section{Conclusions}

Using a model of an exchange economy motivated by Shin (1994), we investigate the interaction between the voluntary disclosure and the subsequent mandatory disclosure of valuerelevant information. We assume that the manager receives a private signal that helps him to assess the likelihood that each value will occur and to get a sense of his managerial ability. The manager has the option of issuing a voluntary disclosure of the firm's earnings after observing 
the signal. Then he has to make a mandatory disclosure of the earnings after he observes the realization of the true earnings. The manager has the flexibility to manage the mandatory disclosure with some success probability to make it line up with his voluntary disclosure to avoid the penalty arising from an earnings disappointment. We show that, in equilibrium, allowing the manager some discretion over the mandatory financial report enables him to incorporate private information into his more timely voluntary disclosure and thus enhances the price informativeness of the voluntary disclosure. However, too much discretion is undesirable because it induces the manager to always voluntarily disclose high earnings numbers and ignore his private information. Thus there is a hidden benefit to granting the manager some degree of discretion over his mandatory disclosure, and there is a maximal amount of such discretion that should be tolerated, consistent with the discretion imbedded in GAAP.

Our finding that voluntary and mandatory disclosures complement each other in the sense that the primarily backward-looking and less timely mandatory disclosure allows the manager to disclose voluntarily (and somewhat credibly) forward-looking and timely private information echoes the long-standing view in the accounting literature that the voluntary disclosure serves as a source of new information, while the mandatory disclosure plays an important confirmatory (or disciplinary) role that makes the voluntary disclosure credible and informative (e.g., Sansing 1992; Stocken 2000; Dutta and Gigler 2002). However, we derive this intuition in a completely different setting, and the result that granting some but not too much discretion over the mandatory disclosure has the potential of enabling managers to incorporate more of their private information in the "unrestricted" voluntary disclosure is new.

Our results also have policy implications. From a regulator's perspective, tolerating some degree of earnings management by allowing some discretion in the accounting standards may be desirable if the price informativeness of voluntary disclosures is an important goal. Given that voluntary disclosure is a major source of firms' information and accounts for about $85 \%$ of the firm-provided accounting-based information that investors use (Beyer et. al. 2010), enhancing the informativeness of voluntary disclosures seems to be essential for efficiently allocating the scarce resources. 


\section{REFERENCES:}

Arya, A., J. Glover, and S. Sunder. 1998. Earnings management and the revelation principle. Review of Accounting Studies 3: 7-34.

Arya, A., J. Glover, and S. Sunder. 2003. Are unmanaged earnings always better for shareholders? Accounting Horizons 17: 111-116.

Bagnoli, M., and S. Watts. 2007. Financial reporting and supplemental voluntary disclosures. Journal of Accounting Research 45(5): 885-913.

Ball, R., S. Jayaraman, and L. Shivakumar. 2012. Audited financial reporting and voluntary disclosure as complements: a test of the confirmation hypothesis. Journal of Accounting and Economics 53: 136-166.

Bartov, E., D. Givoly, and C. Hayn. 2002. The reward for meeting-or-beating earnings expectations. Journal of Accounting and Economics 33: 173-204.

Beyer, A. 2009. Capital market prices, management forecasts and earnings management. The Accounting Review 84: 1713-1747.

Beyer, A., D. Cohen, T. Lys, and B. Walther. 2010. The financial reporting environment: review of the recent literature. Journal of Accounting and Economics 40: 296-343.

Beyer, A., and I. Guttman. 2012. Voluntary disclosure, disclosure bias and real effects. Journal of Accounting Research 50: 1141-1177.

Boisits, A. 2013. The disciplining role of mandatory earnings announcements on voluntary earnings forecasts. Working paper. Available at http://arw-suisse.ch/wpcontent/uploads/2013/05/boisits.pdf.

Bowen, R., S. Rajgopal, and M. Venkatachalam. 2008. Accounting discretion, corporate governance, and firm performance. Contemporary Accounting Research 25 (2): 351-405.

Burgstahler, D., and I. Dichev. 1997. Earnings management to avoid earnings decreases and losses. Journal of Accounting and Economics 24: 99-126. 
Carter, M., L. Lynch, and I. Tuna. 2007. The role of accounting in the design of CEO equity compensation. The Accounting Review 82: 327-357.

Chen, Q., T. Hemmer, and Y. Zhang. 2007. On the relation between conservatism in accounting standards and incentives for earnings management. Journal of Accounting Research 45: $541-565$.

Chen, Q., Z. Huang, and Y. Zhang. 2012. The effects of public information with asymmetrically informed investors. Working Paper, Duke University and George Washington University.

Cho, I.-K., and D. Kreps. 1987. Signaling games and stable equilibria. The Quarterly Journal of Economics 102(2): 179-221.

Degeorge, F., J. Patel, and R. Zeckhauser. 1999. Earnings manipulation to exceed thresholds. Journal of Business 71: 1-34.

Drymiotes, G., and T. Hemmer. 2013. On the stewardship and valuation implications of accrual accounting systems. Journal of Accounting Research 51: 281-334.

Dutta, S., and F. Gigler. 2002. The effect of earnings forecast on earnings management. Journal of Accounting Research 40: 631-655.

Dye, R. 1985. Disclosure of non-proprietary information. Journal of Accounting Research 23: $123-145$.

Dye, R. 1988. Earnings management in an overlapping generations model. Journal of Accounting Research 26: 195-235.

Dye, R., and S. Sridhar. 2008. A positive theory of flexibility in accounting standards. Journal of Accounting and Economics 46: 312-333.

Dye, R., and R. Verrecchia. “Discretion vs. Uniformity: Choices among GAAP.” The Accounting Review 70 (1995): 389-415.

Einhorn, E. 2005. The nature of the interaction between mandatory and voluntary disclosures. Journal of Accounting Research 43(4): 593-621. 
Einhorn, E., and A. Ziv. 2012. Biased voluntary disclosure. Review of Accounting Studies 17: $420-442$.

Ewert, R., and A. Wagenhofer. 2005. Economic effects of tightening accounting standards to restrict earnings management. The Accounting Review 80: 1101-1124.

Ewert, R., and A. Wagenhofer. 2013. Accounting standards, earnings management, and earnings quality. Working paper. Available at http://papers.ssrn.com/sol3/papers.cfm?abstract_id=2068134.

Fischer, P., and P. Stocken. 2004. Effects of investor speculation on earnings management. Journal of Accounting Research 42: 843-870.

Fischer, P., and R. Verrecchia. 2000. Reporting bias. The Accounting Review 75(2): 229-245.

Fishman, M., and K. Hagerty. 1990. The optimal amount of discretion to allow in disclosure. Quarterly Journal of Economics 105: 427-444.

Francis. J., P. Olsson, and D. Nanda. 2008. Voluntary disclosure, earnings quality, and costs of capital. Journal of Accounting Research 46: 53-99.

Grossman, S. 1981. The informational role of warranties and private disclosure about product quality. Journal of Law and Economics 24: 461-483.

Gao, P. 2008. Keynesian beauty contest, accounting disclosure and market efficiency. Journal of Accounting Research 46: 785-807.

Gao, P. 2013. A measurement approach to conservatism and earnings management. Journal of Accounting and Economics 55(2-3): 251-268.

Gigler, F., and T. Hemmer. 1998. On the frequency, quality and informational role of mandatory financial reports. Journal of Accounting Research 36:117-147.

Gigler, F., and X. Jiang. 2015. Necessary qualities of accounting information to serve a confirmatory role. Working Paper, University of Minnesota and Duke University. 
Govindan, S., and R. Wilson. 2006. Sufficient conditions for stable equilibria. Theoretical Economics 1: 167-206.

Guttman, I., O. Kadan and E. Kandel. 2006. A rational expectations theory of the kinks in financial reporting. The Accounting Review 81: 811-848

Hui, W.H., S. Matsunaga, and D. Morse. 2009. The impact of conservatism on management earnings forecasts. Journal of Accounting \& Economics 47: 192-207.

Jung, W., and Y. Kwon. 1988. Disclosure when the market is unsure of information endowment of managers. Journal of Accounting Research 26: 146-153.

Kasznik, R. 1999. On the association between voluntary disclosure and earnings management. Journal of Accounting Research 37: 57-81.

Kim, J. 2012. Accounting flexibility and managers' forecast behavior prior to seasoned equity offerings. Working Paper, Singapore Management University. Available at http://papers.ssrn.com/sol3/papers.cfm?abstract_id=1754592.

Korn, E. 2004. Volunatry disclosure of partially verifiable information. Schmalenbach Business Review 56: 139-163.

Kwon, Y.K., P. Newman, and Y. Zang. 2009. The effect of accounting report quality on the bias in and likelihood of management disclosures. Working paper, University of Illinois, University of Texas at Austin, and Singapore Management University. Available at http://papers.ssrn.com/sol3/papers.cfm?abstract_id=1399863.

Laux, V., and P. Stocken. 2012. Managerial reporting, overoptimism, and litigation risk. Journal of Accounting \& Economics 53 (3): 577-591.

Levitt, A. 1998. The numbers game. Securities and Exchange Commission, Remarks by Chair Arthur Levitt at New York University Center of Law and Business (September 28).

Lundholm, R. 2003. Historical accounting and the endogenous credibility of current disclosures. Journal of Accounting, Auditing \& Finance 18(1): 207-229. 
Rogers, J., and P. Stocken. 2005. Credibility of management forecasts. The Accounting Review 80: $1233-1260$.

Roychowdhury, S. 2006. Earnings management through real activities manipulation. Journal of Accounting and Economics 42: 335-370.

Sankar, M., and K. Subramanyam. 2001. Reporting discretion and private information communication through earnings. Journal of Accounting Research 39: 365-386.

Sansing, R. 1992, Accounting and the credibility of management forecasts. Contemporary Accounting Research 9: 33-45.

Schipper, K. 1989. Commentary on earnings management. Accounting Horizons 3: 91-102.

Shin, H. 1994. News management and the value of the firm. Rand Journal of Economics 25: $58-71$.

Stocken, P. 2000. Credibility of voluntary disclosure. Rand Journal of Economics 31: 359-374.

Stocken, P. 2013. Strategic accounting disclosure. In Foundations and Trends in Accounting 7 (4), 197-291. Hanover, MA: Now Publishers Inc.

Stocken, P., and R. Verrecchia. 2004. Financial reporting system choice and disclosure management. Review of Accounting Studies 79: 1181-1203.

Trueman, B., and S. Titman. 1988. An explanation for accounting income smoothing. Journal of Accounting Research 26: 127-139.

Verrecchia, R. 1983. Discretionary disclosure. Journal of Accounting and Economics 5: 179194. 
Appendix A: A summary of notations used in the paper

\begin{tabular}{|c|c|}
\hline Notation & Meaning of the notation \\
\hline$x_{i}, i=H, L$ & $\begin{array}{l}\text { True Earnings which depends on the } \\
\text { underlying state } i \text {. We sometimes also use } x \\
\text { to refer to true earnings in general. }\end{array}$ \\
\hline$p_{i}, i=H, L$ & Prior probability of the firm being in state $i$. \\
\hline$\sigma(i), i=H, L$ & $\begin{array}{l}\text { A perfectly informative signal about the true } \\
\text { earnings defined by equation (1). }\end{array}$ \\
\hline$\theta$ & Probability of observing $\sigma(i)$. \\
\hline$s \in\{h, l\}$ & $\begin{array}{l}\text { A noisy signal about the true earnings when } \\
\sigma(i) \text { cannot be observed. }\end{array}$ \\
\hline$q$ & $\begin{array}{l}\text { The informativeness of } s \text { about true earnings, } \\
\text { as defined in equation (2). }\end{array}$ \\
\hline$p_{i j}, i=H, L ; j=h, l$ & $\begin{array}{l}p\left(x=x_{i} \mid s=j\right), \text { i.e., manager's perceived } \\
\text { probability of } x=x_{i} \text { conditional on } \\
\text { observing } s=j\end{array}$ \\
\hline$a_{j}, j=1,2,3$ & $\begin{array}{l}\text { Manager's ability, which determines both the } \\
\text { probability of generating high true earnings } \\
\text { and the probability of observing } \sigma(i) \text {. }\end{array}$ \\
\hline$\Omega$ & $\begin{array}{l}\text { Manager's information set before voluntary } \\
\text { disclosure. }\end{array}$ \\
\hline$D_{i}, i=H, L$ & $\begin{array}{l}\text { Voluntary disclosure of true earnings number } \\
\text { being at least } x_{i} \text {. We sometimes also use } D \text { to } \\
\text { refer to voluntary disclosure in general. }\end{array}$ \\
\hline$R(D, x)$ & $\begin{array}{l}\text { Manager's mandatory disclosure strategy, } \\
\text { which is a function of his voluntary } \\
\text { disclosure strategy } D \text { and true earnings } \\
\text { number } x \text {. Manager's mandatory disclosure } \\
\text { strategy and his earnings management } \\
\text { strategy jointly determine the distribution of } \\
\text { the realized mandatory disclosure. }\end{array}$ \\
\hline
\end{tabular}




\begin{tabular}{|c|l|}
\hline \multicolumn{1}{|c|}{$(D, x)$} & $\begin{array}{l}\text { Investors' conjecture about manager's } \\
\text { mandatory disclosure strategy. }\end{array}$ \\
\hline$m(D, R, x) \in\{0,1\}$ & $\begin{array}{l}\text { Manager's earnings management decision as } \\
\text { a function of his voluntary disclosure } \\
\text { strategy, mandatory disclosure strategy and } \\
\text { true earnings. } m(D, R, x)=0(1) \text { represents } \\
\text { no earnings management (earnings } \\
\text { management). }\end{array}$ \\
\hline$\hat{m}(D, R, x) \in\{0,1\}$ & $\begin{array}{l}\text { Investors' conjecture about manager's } \\
\text { earnings management decision. }\end{array}$ \\
\hline$\delta$ & $\begin{array}{l}\text { Probability of successful upward earnings } \\
\text { management. }\end{array}$ \\
\hline$R_{i}, i=H, L$ & $\begin{array}{l}\text { Realization of mandatory disclosure } x_{i} . \text { We } \\
\text { sometimes also use } R \text { to refer to realization } \\
\text { of mandatory disclosure in general. }\end{array}$ \\
\hline$P(D, R ; m)$ & $\begin{array}{l}\text { Price response when the voluntary disclosure } \\
\text { is } D \text {, the realization of mandatory disclosure } \\
\text { is } R \text { and the manager's manipulation strategy } \\
\text { is } m .\end{array}$ \\
\hline$\hat{P}(D, R ; m)$ & $\begin{array}{l}\text { Manager's conjecture about investor's price } \\
\text { response. }\end{array}$ \\
\hline$U_{i j} \equiv P\left(D_{i}, R_{j} ; m\right)+\lambda E\left[a \mid D_{i}, R_{j}\right], i, j=H, L$ & $\begin{array}{l}\text { Relative weight that manager places on the } \\
\text { perceived ability in his payoff function. } \\
\text { and the realization of mandatory disclosure } \\
R_{j} .\end{array}$ \\
\hline & $\begin{array}{c}\text { Mangers payoff at voluntary disclosure } D_{i} \\
\end{array}$ \\
\hline
\end{tabular}

Furthermore, in general we use $p$ to denote probability, $P$ to denote price, and $E$ to denote expectation. 


\section{Appendix B: Technical Details Including Proofs}

We focus on equilibria in which $P\left(D_{H}\right) \geq P\left(D_{L}\right)$, i.e., $D_{H}$ conveys news that is perceived at least as good as that of $D_{L}$.

Lemma 1. $P\left(D_{H}\right) \geq P\left(D_{L}\right)$ implies that in equilibrium it cannot be the case for a manager observing $\sigma=1(\sigma=0)$ to strictly prefer disclosing $D_{L}\left(D_{H}\right)$.

\section{Proof of Lemma 1:}

Suppose this is true. $P\left(D_{H}\right)$ and $P\left(D_{L}\right)$ then depends on the strategy of the manager who observes $S$. There are four possible cases.

Case 1: The manager who observes $s$ always discloses $D_{H}$ regardless of what $s$ is. This however cannot be sustained in equilibrium as $P\left(D_{L}\right)=x_{H}>P\left(D_{H}\right)$.

Case 2: The manager who observes $s$ always discloses $D_{L}$ regardless of what $s$ is. This however cannot be sustained in equilibrium as $P\left(D_{H}\right)=x_{L}<P\left(D_{L}\right)$.

Case 3: The manager who observes $s=h$ and $s=l$ discloses $D_{L}$ and $D_{H}$ respectively. This results in:

$$
\begin{aligned}
& p\left(x_{H} \mid D_{L}\right)=\frac{p\left(D_{L} \mid x_{H}\right) p_{H}}{p\left(D_{L} \mid x_{H}\right) p_{H}+p\left(D_{L} \mid x_{L}\right) p_{L}}=\frac{(1-(1-\theta)(1-q)) p_{H}}{(1-(1-\theta)(1-q)) p_{H}+(1-\theta)(1-q) p_{L}}=\frac{1}{1+\frac{(1-\theta)(1-q)}{1-(1-\theta)(1-q)} \frac{p_{L}}{p_{H}}}, \text { and, } \\
& p\left(x_{H} \mid D_{H}\right)=\frac{p\left(D_{H} \mid x_{H}\right) p_{H}}{p\left(D_{H} \mid x_{H}\right) p_{H}+p\left(D_{H} \mid x_{L}\right) p_{L}}=\frac{(1-\theta)(1-q) p_{H}}{(1-\theta)(1-q) p_{H}+(1-(1-\theta)(1-q)) p_{L}}=\frac{1}{1+\frac{1-(1-\theta)(1-q)}{(1-\theta)(1-q)} \frac{p_{L}}{p_{H}}} .
\end{aligned}
$$

Since $\frac{(1-\theta)(1-q)}{1-(1-\theta)(1-q)}<\frac{1-(1-\theta)(1-q)}{(1-\theta)(1-q)}, p\left(x_{H} \mid D_{L}\right)>p\left(x_{H} \mid D_{H}\right)$, thus $P\left(D_{L}\right)>P\left(D_{H}\right)$, which contradicts $P\left(D_{H}\right) \geq P\left(D_{L}\right)$. 
Case 4: The manager who observes $s=h$ and $l$ discloses $D_{H}$ and $D_{L}$ respectively. Similarly:

$$
p\left(x_{H} \mid D_{L}\right)=\frac{1}{1+\frac{(1-\theta) q}{(1-(1-\theta) q)} \frac{p_{L}}{p_{H}}}, \text { and, } p\left(x_{H} \mid D_{H}\right)=\frac{1}{1+\frac{1-(1-\theta) q}{(1-\theta) q} \frac{p_{L}}{p_{H}}} \text {. }
$$

$$
\text { When } \frac{(1-\theta) q}{(1-(1-\theta) q)}<\frac{1-(1-\theta) q}{(1-\theta) q}, p\left(x_{H} \mid D_{L}\right)>p\left(x_{H} \mid D_{H}\right) \text {, thus } P\left(D_{L}\right)>P\left(D_{H}\right) \text {, which }
$$
again contradicts $P\left(D_{H}\right) \geq P\left(D_{L}\right)$.

(ii) When $\frac{(1-\theta) q}{(1-(1-\theta) q)} \geq \frac{1-(1-\theta) q}{(1-\theta) q}$, or, equivalently, $(1-\theta) q \geq \frac{1}{2}, P\left(D_{H}\right) \geq P\left(D_{L}\right)$.

However this strategy cannot be sustained in equilibrium because the manager who observes $\sigma=1$ will have incentive to switch from $D_{L}$ to $D_{H}$. The reason is as follows. First, switching gives a higher price response. Second, switching does not decrease the manager's perceived ability because a manager who observes $\sigma=1$ will always have $x=x_{H}$. When no reporting discretion is allowed, $E\left[a \mid D_{L}, R_{H}\right]=$ $E\left[a \mid D_{H}, R_{H}\right]=a_{3}$. When reporting discretion is allowed, as will be shown below, every manager type with $x=x_{L}$ will manage earnings upward. Then, following the conjectured strategy, $\left\{D_{L}, R_{H}\right\}$ implies that manager can be of either $a_{3}$ (i.e., $x=x_{H}$ ) or $a_{1}$ (i.e., $x=x_{L}, s=l$ is observed, and earnings management is successful). This gives:

$$
\begin{aligned}
& p\left(a_{3} \mid D_{L}, R_{H}\right)=\frac{p\left(D_{L}, R_{H} \mid a_{3}\right) p\left(a_{3}\right)}{p\left(D_{L}, R_{H} \mid a_{1}\right) p\left(a_{1}\right)+p\left(D_{L}, R_{H} \mid a_{3}\right) p\left(a_{3}\right)}=\frac{p_{H}}{p_{H}+\delta p_{L}(1-\theta) q}, \text { and, } \\
& p\left(a_{1} \mid D_{L}, R_{H}\right)=\frac{p\left(D_{L}, R_{H} \mid a_{1}\right) p\left(a_{1}\right)}{p\left(D_{L}, R_{H} \mid a_{1}\right) p\left(a_{1}\right)+p\left(D_{L}, R_{H} \mid a_{3}\right) p\left(a_{3}\right)}=\frac{p p_{L}(1-\theta) q}{p_{H}+\delta p_{L}(1-\theta) q} .
\end{aligned}
$$


Similarly, following the conjectured strategy, observing $\left\{D_{H}, R_{H}\right\}$ implies that the manager can be of $a_{3}$ (i.e., $x=x_{H}$ ), $a_{2}$ (i.e., $x=x_{L}$ and $\sigma=0$ is observed), or $a_{1}$ (i.e., $x=x_{L}$ and $s=h$ is observed). This gives:

$$
\begin{aligned}
& p\left(a_{3} \mid D_{H}, R_{H}\right)=\frac{p_{H}}{p_{H}+\delta p_{L}(1-(1-\theta) q)}, p\left(a_{2} \mid D_{H}, R_{H}\right)=\frac{\delta p_{L} \theta}{p_{H}+\delta p_{L}(1-(1-\theta) q)}, \text { and } \\
& p\left(a_{1} \mid D_{H}, R_{H}\right)=\frac{\delta p_{L}(1-\theta)(1-q)}{p_{H}+\delta p_{L}(1-(1-\theta) q)}
\end{aligned}
$$

Since $(1-\theta) q \geq \frac{1}{2},(1-\theta) q \geq 1-(1-\theta) q$. This indicates $p\left(a_{3} \mid D_{H}, R_{H}\right) \geq$ $p\left(a_{3} \mid D_{L}, R_{H}\right)$. Thus $E\left[a \mid D_{H}, R_{H}\right] \geq E\left[a \mid D_{L}, R_{H}\right]$. This means that the manager who observes $\sigma=1$ is better off by deviating to disclosing $D_{H}$. Q.E.D.

Assuming that the manager who observes $\sigma=1(\sigma=0)$ discloses $D_{H}\left(D_{L}\right)$ when indifferent between $D_{H}$ and $D_{L}$, Lemma 1 implies that only three cases are possible in equilibrium when $\sigma$ is observed: (1) The manager discloses $D_{L}$ regardless of $\sigma$; (2) The manager discloses $D_{H}$ regardless of $\sigma$; and (3) The manager discloses $D_{H}$ if $\sigma=1$ and $D_{L}$ if $\sigma=0$. We will use this result in the subsequent analysis.

\section{Proof of Proposition 1:}

When no discretion is allowed, $E[\tilde{x} \mid D, R]=R, \forall D, R$. Thus $E[E[\tilde{x} \mid D, R] \mid \Omega]=E[R \mid \Omega]$. Manager's choice of $D$ has no effect on the price of the firm. Therefore, the manager chooses $D$ to maximize investor's perceived ability of him, $E[E[a \mid D, R] \mid \Omega]$.

First we introduce some notations. Let $p_{H h} \equiv p\left(x_{H} \mid h\right)=\frac{p\left(h \mid x_{H}\right) p_{H}}{p\left(h \mid x_{H}\right) p_{H}+p\left(h \mid x_{L}\right) p_{L}}=\frac{q p_{H}}{q p_{H}+(1-q) p_{L}}$ be the probability of $x=x_{H}$ given $s=h$ is observed, and $p_{H l} \equiv p\left(x_{H} \mid l\right)=\frac{p\left(l \mid x_{H}\right) p_{H}}{p\left(l \mid x_{H}\right) p_{H}+p\left(l \mid x_{L}\right) p_{L}}=$ 
$\frac{(1-q) p_{H}}{(1-q) p_{H}+q p_{L}}$ be the probability of $x=x_{H}$ given $s=l$ is observed. Define the manager's type by his private signal of the true earnings at the time of voluntary disclosure (e.g., manager of type $s=h$ means a manager who does not observe $\sigma$, but observes $s=h$ ). Let's rewrite $E\left[E\left[a \mid D_{i}, R\right] \mid s=j\right]$ as $E\left[a \mid D_{i}, s=j\right]$ for $i=H, L$ and $j=h, l$ when this does not generate confusion.

There are then four manager types: $\sigma=1 ; \sigma=0 ; s=h$; and $s=l . P\left(D_{H}\right) \geq P\left(D_{L}\right)$ implies that if manager of type $\sigma=0$ discloses $D_{H}$, then manager of type $\sigma=1$ also discloses $D_{H}$. However, if manager of type $\sigma=0$ discloses $D_{L}$, then manager of type $\sigma=1$ can disclose either $D_{H}$ or $D_{L}$.

We characterize all pure strategy equilibria by examining all possible cases. Each case would contain a strategy profile of the manager that is allowed under $P\left(D_{H}\right) \geq P\left(D_{L}\right)$. In each case we start with each manager type choosing the strategy specified and calculate his corresponding payoff. We then check whether there exists any type that has an incentive to deviate from the specified strategy - if this is true, then such a strategy cannot be an equilibrium strategy. All the pure strategies that survive this check are equilibrium pure strategies.

Case 1: The manager discloses either $D_{L}$ or $D_{H}$, regardless of his type. $D$ thus has no information content, and $E[a \mid D, R]=\left\{\begin{array}{ll}a_{1} \frac{p\left(a_{1}\right)}{p\left(a_{1}\right)+p\left(a_{2}\right)}+a_{2} \frac{p\left(a_{2}\right)}{p\left(a_{1}\right)+p\left(a_{2}\right)} & \text { for } R_{L} \\ a_{3} & \text { for } R_{H}\end{array}, \forall D\right.$. This strategy is sustained in equilibrium since switching to an alternative strategy generates the same payoff. We denote this equilibrium "uninformative equilibrium."

Case 2: Manager of type $\sigma=1$ or $\sigma=0$ discloses $D_{L}$, and all other types disclose $D_{H}$. 
In this case $E\left[a \mid D_{L}, R_{L}\right]=a_{2}, E\left[a \mid D_{L}, R_{H}\right]=a_{3}, E\left[a \mid D_{H}, R_{L}\right]=a_{1}$, and $E\left[a \mid D_{H}, R_{H}\right]=a_{3}$. Note, however, this strategy cannot be an equilibrium strategy as manager of type $s=h$ will deviate from $D_{H}$ to $D_{L}$ because

$$
E\left[a \mid D_{L}, s=h\right]=\left(1-p_{H h}\right) E\left[a \mid D_{L}, R_{L}\right]+p_{H h} E\left[a \mid D_{L}, R_{H}\right]=\left(1-p_{H h}\right) a_{2}+p_{H h} a_{3}
$$

$>\left(1-p_{H h}\right) a_{1}+p_{H h} a_{3}=\left(1-p_{H h}\right) E\left[a \mid D_{H}, R_{L}\right]+p_{H h} E\left[a \mid D_{H}, R_{H}\right]=E\left[a \mid D_{H}, s=h\right]$.

Case 3: Manager of type $\sigma=0$ discloses $D_{L}$, and all other types disclose $D_{H}$.

We denote this strategy as "reverse sanitization strategy" because this strategy is exactly the opposite of "sanitization strategy" of Shin (1994) in the sense that the manager will disclose $D_{L}$ only when he is completely certain that $x=x_{L}$.

In this case, $E\left[a \mid D_{L}, R_{L}\right]=a_{2}, E\left[a \mid D_{H}, R_{L}\right]=a_{1}$, and $E\left[a \mid D_{H}, R_{H}\right]=a_{3}$.

Note that $\left\{D_{L}, R_{H}\right\}$ is not expected to be observed under this strategy. Further, $E\left[a \mid D_{L}, R_{H}\right]=$ $a_{3}$ (i.e., when $R_{H}$ is reported, the investor believes that $D_{L}$ is mistakenly made by a manager of $a_{3}$ since $x=x_{H}$ has to come from a manager of $a_{3}$ ). However, this strategy cannot be an equilibrium strategy as manager of type $s=h$ has an incentive to deviate from $D_{H}$ to $D_{L}$ because $E\left[a \mid D_{L}, s=h\right]=\left(1-p_{H h}\right) a_{2}+p_{H h} a_{3}>\left(1-p_{H h}\right) a_{1}+p_{H h} a_{3} E\left[a \mid D_{H}, s=h\right]$.

Case 4: Manager of type $\sigma=0$ or $s=l$ discloses $D_{L}$, and all other types disclose $D_{H}$.

In this case, $E\left[a \mid D_{H}, R_{L}\right]=a_{1}, E\left[a \mid D_{L}, R_{H}\right]=E\left[a \mid D_{H}, R_{H}\right]=a_{3}$, and $E\left[a \mid D_{L}, R_{L}\right]=$ $a_{1} p\left(a_{1} \mid D_{L}, R_{L}\right)+a_{2} p\left(a_{2} \mid D_{L}, R_{L}\right)$.

By Bayes' Rule, $p\left(a_{1} \mid D_{L}, R_{L}\right)=\frac{p\left(D_{L}, R_{L} \mid a_{1}\right) p\left(a_{1}\right)}{p\left(D_{L}, R_{L} \mid a_{1}\right) p\left(a_{1}\right)+p\left(D_{L}, R_{L} \mid a_{2}\right) p\left(a_{2}\right)}=\frac{q p_{L}(1-\theta)}{q p_{L}(1-\theta)+p_{L} \theta}$. 
Thus, $E\left[a \mid D_{L}, R_{L}\right]=a_{1} \frac{q p_{L}(1-\theta)}{q p_{L}(1-\theta)+p_{L} \theta}+a_{2} \frac{p_{L} \theta}{q p_{L}(1-\theta)+p_{L} \theta}$.

Note however, this strategy cannot be an equilibrium strategy as manager of type $s=h$ will deviate from $D_{H}$ to $D_{L}$ because

$E\left[a \mid D_{L}, s=h\right]=\left(1-p_{H h}\right)\left(a_{1} \frac{q p_{L}(1-\theta)}{q p_{L}(1-\theta)+p_{L} \theta}+a_{2} \frac{p_{L} \theta}{q p_{L}(1-\theta)+p_{L} \theta}\right)+p_{H h} a_{3}$

$>\left(1-p_{H h}\right) a_{1}+p_{H h} a_{3}=E\left[a \mid D_{H}, s=h\right]$.

Case 5: Manager of type $\sigma=0$ or $s=h$ discloses $D_{L}$, and all other types disclose $D_{H}$.

In this case $E\left[a \mid D_{H}, R_{L}\right]=a_{1}, E\left[a \mid D_{L}, R_{H}\right]=E\left[a \mid D_{H}, R_{H}\right]=a_{3}$, and $E\left[a \mid D_{L}, R_{L}\right]=$ $a_{1} p\left(a_{1} \mid D_{L}, R_{L}\right)+a_{2} p\left(a_{2} \mid D_{L}, R_{L}\right)=a_{1} \frac{(1-q) p_{L}(1-\theta)}{(1-q) p_{L}(1-\theta)+p_{L} \theta}+a_{2} \frac{p_{L} \theta}{(1-q) p_{L}(1-\theta)+p_{L} \theta}$. Note however, this strategy cannot be an equilibrium strategy as manager of type $s=l$ will deviate from $D_{H}$ to $D_{L}$ because $E\left[a \mid D_{L}, s=l\right]=\left(1-p_{H l}\right) E\left[a \mid D_{L}, R_{L}\right]+p_{H l} E\left[a \mid D_{L}, R_{H}\right]$

$=\left(1-p_{H l}\right)\left(a_{1} \frac{(1-q) p_{L}(1-\theta)}{(1-q) p_{L}(1-\theta)+p_{L} \theta}+a_{2} \frac{p_{L} \theta}{(1-q) p_{L}(1-\theta)+p_{L} \theta}\right)+p_{H l} a_{3}$

$>\left(1-p_{H l}\right) a_{1}+p_{H l} a_{3}=\left(1-p_{H l}\right) E\left[a \mid D_{H}, R_{L}\right]+p_{H l} E\left[a \mid D_{H}, R_{H}\right]=E\left[a \mid D_{H}, s=h\right]$.

Case 6: Manager of type $\sigma=1$ discloses $D_{H}$, and all other types disclose $D_{L}$.

We denote this strategy as "sanitization strategy."

Note in this case $\left\{D_{H}, R_{L}\right\}$ is on off-equilibrium path. As will be clear shortly, the offequilibrium belief that supports this equilibrium is $E\left[a \mid D_{H}, R_{L}\right] \leq a_{1}(1-\theta)+a_{2} \theta$, an assumption that we maintain. 
In this case, $E\left[a \mid D_{H}, R_{H}\right]=E\left[a \mid D_{L}, R_{H}\right]=a_{3}$, and $E\left[a \mid D_{L}, R_{L}\right]=a_{1} p\left(a_{1} \mid D_{L}, R_{L}\right)+$ $a_{2} p\left(a_{2} \mid D_{L}, R_{L}\right)=a_{1}(1-\theta)+a_{2} \theta$ since $p\left(a_{1} \mid D_{L}, R_{L}\right)=$ $\frac{p\left(D_{L}, R_{L} \mid a_{1}\right) p\left(a_{1}\right)}{p\left(D_{L}, R_{L} \mid a_{1}\right) p\left(a_{1}\right)+p\left(D_{L}, R_{L} \mid a_{2}\right) p\left(a_{2}\right)}=\frac{1 \times p_{L}(1-\theta)}{1 \times p_{L}(1-\theta)+1 \times p_{L} \theta}=1-\theta$.

Manager of type $\sigma=1$ knows that he is of $a_{3}$, and he is indifferent between $D_{H}$ and $D_{L}$ as $E\left[a \mid D_{H}, R_{H}\right]=a_{3}=E\left[a \mid D_{L}, R_{H}\right]$.

Manager of type $\sigma=0$ knows that he is of $a_{2}$, and he prefers $D_{L}$ over $D_{H}$ as $E\left[a \mid D_{L}, R_{L}\right]=$ $a_{1}(1-\theta)+a_{2} \theta \geq E\left[a \mid D_{H}, R_{L}\right]$ by assumption.

For manager of type $s=h, E\left[a \mid D_{L}, s=h\right]=\left(1-p_{H h}\right) E\left[a \mid D_{L}, R_{L}\right]+p_{H h} E\left[a \mid D_{L}, R_{H}\right]=$ $\left(1-p_{H h}\right)\left(a_{1}(1-\theta)+a_{2} \theta\right)+p_{H h} a_{3} \geq\left(1-p_{H h}\right) E\left[a \mid D_{H}, R_{L}\right]+p_{H h} a_{3}$ $=\left(1-p_{H h}\right) E\left[a \mid D_{H}, R_{L}\right]+p_{H h} E\left[a \mid D_{H}, R_{H}\right]=E\left[a \mid D_{H}, s=h\right]$.

For manager of type $s=l, E\left[a \mid D_{L}, s=l\right]=\left(1-p_{H l}\right)\left(a_{1}(1-\theta)+a_{2} \theta\right)+p_{H l} a_{3} \geq$ $\left(1-p_{H l}\right) E\left[a \mid D_{H}, R_{L}\right]+p_{H l} a_{3}=E\left[a \mid D_{H}, s=l\right]$

Therefore, the sanitization strategy can be supported when the off-equilibrium belief satisfies $E\left[a \mid D_{H}, R_{L}\right] \leq a_{1}(1-\theta)+a_{2} \theta$

To summarize, there are two pure strategy equilibria. One is the "uninformative equilibrium" where voluntary disclosure is completely uninformative (Case 1), and the other is the "sanitization equilibrium" (Case 6). We show below that both equilibria can be eliminated using the Cho-Kreps intuitive criterion. For the "uninformative equilibrium," suppose that every manager type discloses $D_{L}$ regardless of his private signal. This results in $E\left[a \mid D_{L}, R\right]=$ $E[a \mid R]$. But then the manager of type $\sigma=0$ has an incentive to deviate and disclose $D_{H}$ as this 
type has $a_{2}>E\left[a \mid R_{L}\right]$. Similar reasoning can be applied to eliminating the equilibrium in which $D_{H}$ is disclosed. For the "sanitization equilibrium," the off-equilibrium message $\left\{D_{H}, R_{L}\right\}$ can only possibly be sent by manager of type $\sigma=0$, or $s=h$, or $s=l$. Manager of type $s=h$ or $s=l$ has no incentive to deviate, so this message, if sent, must come from manager of type $\sigma=0$. This results in $E\left[a \mid D_{H}, R_{L}\right]=a_{2}>a_{1}(1-\theta)+a_{2} \theta$. We thus conclude that both pure strategy equilibria can be eliminated by the intuitive criterion. Q.E.D.

When introducing the reporting discretion, the number of manager's possible strategies increases. Before proving Proposition 2 that characterizes all the possible pure strategy equilibria under $P\left(D_{H}\right) \geq P\left(D_{L}\right)$, we first state and prove three lemmas, which restrict the possible strategies that the manager can adopt. Let $U_{t v} \equiv E\left[\tilde{x}+\lambda a \mid D_{t}, R_{v}\right]$ be the manager's payoff at $D_{t}$ and $R_{v}$, for $t, v=H, L$.

Lemma 2 In any equilibrium, it is not feasible for manager of type $\sigma=1$ or $\sigma=0$ to disclose $D_{H}$, while manager of type $s=h$ or $s=l$ to disclose $D_{L}$; and vice versa.

\section{Proof of Lemma 2:}

We present the proof for the first part (the proof for the second part is essentially the same). Suppose manager of type $\sigma=1$ or $\sigma=0$ discloses $D_{H}$ while manager of type $s=h$ or $s=l$ discloses $D_{L}$. This implies that $U_{H H}>U_{L H}$ and $U_{H L}>U_{L L}$. But then manager of type $s=h$ or $s=l$ will not choose $D_{L}$ as choosing $D_{H}$ becomes a dominant strategy. Q.E.D.

Note that Lemma 2 implies that we can focus on strategies where all types of manager disclose $D_{H}$, or all types of manager disclose $D_{L}$, or manager of type $\sigma=1$ discloses $D_{H}$ and manager of type $\sigma=0$ discloses $D_{L}$. 
Lemma 3 If any two or more manager types issue the same voluntary disclosure, then it must be the case that: either all these manager types issuing the same voluntary disclosure manage earnings upward when $x=x_{L}$ (and do not manage earnings when $x=x_{H}$ ), or none of these manager types manages earnings regardless of $x$. In other words, it cannot be the case that one type of manager manage earnings upward but another type does not for $x=x_{L}$ when the same voluntary disclosure is made by these types.

\section{Proof of Lemma 3:}

Suppose not. Then there exists an equilibrium where two manager types make the same voluntary disclosure, but one type manages earnings upward and the other does not for $x=x_{L}$. We present reasoning for one case. Suppose that manager of types $\sigma=0$ and $s=h$ discloses $D_{L}$, and while type $\sigma=0$ manages earnings upward, type $s=h$ does not when $x=x_{L}$. This implies that $\delta U_{L H}+(1-\delta) U_{L L}>U_{L L}$, or equivalently, $U_{L H}>U_{L L}$. But then the manager of type $s=h$ would find it beneficial to manage earnings upward when $x=x_{L}$ since his expected payoff from earnings management is larger, i.e., $\left(1-\left(1-p_{H h}\right)(1-\delta)\right) U_{L H}+(1-$ $\left.p_{H h}\right)(1-\delta) U_{L L}>p_{H h} U_{L H}+\left(1-p_{H h}\right) U_{L L}$.

All other feasible cases can be proved analogously. Q.E.D.

Lemma 4 In any pure strategy equilibrium, the manager engages in upward earnings management when $x=x_{L}$.

\section{Proof of Lemma 4:}

Suppose not. Then there exists at least one pure strategy equilibrium in which at least one type of manager does not manage earnings upward when $x=x_{L}$. This implies that either $U_{H H}<$ 
$U_{H L}$ or $U_{L H}<U_{L L}$ or both. Suppose $U_{H H}<U_{H L}$. This implies that the manager who voluntarily discloses $D_{H}$ can benefit from managing earnings downward. However, this cannot be true because if $x=x_{H}$, he knows that he is of $a_{3}$, which is larger than the average ability of pooling with other lower types by managing earnings downward. In addition, $E\left[\tilde{x} \mid D_{H}, R_{H}\right]=x_{H}$ given that the manager who discloses $D_{H}$ manages earnings downward, but does not manage earnings upward. We therefore have a contradiction. The case $U_{L H}<U_{L L}$ can be proved analogously. Q.E.D.

\section{Proof of Proposition 2:}

We solve for the equilibrium using a similar procedure to that used in the proof of Proposition 1. We characterize all possible strategy profiles for all manager types that satisfy both $P\left(D_{H}\right) \geq$ $P\left(D_{L}\right)$ and Lemmas 2 to 4 , and derive expressions for $U_{t v}$ for $t, v=L, H$ assuming each feasible strategy profile is supported in equilibrium. We finally check the constraints that must be satisfied to support the strategy profile in equilibrium. If the constraints are not consistent with each other, then the conjectured strategy profile cannot be an equilibrium strategy profile. We at times go directly to the final step when it is obvious that regardless of the expression for $U_{t v}$, the constraints cannot be consistent with each other.

Lemma 2 implies that manager of type $\sigma=1(\sigma=0)$ chooses $D_{H}\left(D_{L}\right)$. Lemma 3 shows that manager types that issue the same voluntary disclosure also choose the same earnings management strategy (i.e, all or no manage types). Lemma 4 indicates that managing earnings downward can never be an equilibrium solution. Thus there are seven pure strategy profiles that are potentially feasible to the manager: 
Case 1: No type engages in any upward earnings management. This brings us back to Proposition 1 which shows that no pure strategy equilibrium survives the intuitive criterion.

Case 2: Manager of type $\sigma=1$ chooses $D_{H}$ and all other types choose $D_{L}$. The manager who chooses $D_{L}$ manages earnings upward when $x=x_{L}$, and do not manage earnings when $x=x_{H}$. We show this strategy can be sustained in equilibrium and denote this equilibrium as "sanitization with management equilibrium" since the voluntary disclosure strategy is the sanitization strategy. Then we demonstrate how it can be eliminated via intuitive criterion.

This strategy profile implies that $U_{H H}=x_{H}+\lambda a_{3}$. Also $\left\{D_{H}, R_{L}\right\}$ is on off-equilibrium path and as will become clear later, the off-equilibrium beliefs that support this equilibrium are $x_{L}+\lambda a_{1} \leq U_{H L}<x_{L}+\lambda\left(a_{1}(1-\theta)+a_{2} \theta\right)$.

Further, $U_{L L}=x_{L}+\lambda E\left[a \mid D_{L}, R_{L}\right]=x_{L}+\lambda\left(a_{1}(1-\theta)+a_{2} \theta\right)$ since $p\left(a_{1} \mid D_{L}, R_{L}\right)=$ $\frac{p\left(D_{L}, R_{L} \mid a_{1}\right) p\left(a_{1}\right)}{p\left(D_{L}, R_{L} \mid a_{1}\right) p\left(a_{1}\right)+p\left(D_{L}, R_{L} \mid a_{2}\right) p\left(a_{2}\right)}=\frac{p_{L}(1-\theta)}{p_{L}(1-\theta)+p_{L} \theta}=1-\theta$,and, $U_{L H}=E\left[\tilde{x} \mid D_{L}, R_{H}\right]+$ $\lambda E\left[a \mid D_{L}, R_{H}\right]=x_{H} \frac{(1-\theta) p_{H}}{(1-\theta) p_{H}+\delta p_{L}}+x_{L} \frac{\delta p_{L}}{(1-\theta) p_{H}+\delta p_{L}}+\lambda\left(a_{1} \frac{\delta p_{L}(1-\theta)}{(1-\theta) p_{H}+\delta p_{L}}+a_{2} \frac{\delta p_{L} \theta}{(1-\theta) p_{H}+\delta p_{L}}+\right.$ $\left.a_{3} \frac{(1-\theta) p_{H}}{(1-\theta) p_{H}+\delta p_{L}}\right)$

For this equilibrium to be sustainable, the following condition must be met:

$U_{H H}-U_{L H}<\frac{\left(1-p_{H h}\right)(1-\delta)}{1-\left(1-p_{H h}\right)(1-\delta)}\left(U_{L L}-U_{H L}\right)$, or, equivalently, $\left(x_{H}-x_{L}+\lambda\left(a_{3}-a_{2}\right)\right) \frac{\delta p_{L}}{(1-\theta) p_{H}+\delta p_{L}}+\lambda\left(a_{2}-a_{1}\right) \frac{\delta p_{L}(1-\theta)}{(1-\theta) p_{H}+\delta p_{L}}<\frac{\left(1-p_{H h}\right)(1-\delta)}{1-\left(1-p_{H h}\right)(1-\delta)}\left(U_{L L}-U_{H L}\right)$.

It can be shown that $U_{L L}-U_{H L}>0$. Thus, the proper off-equilibrium belief to sustain this equilibrium is that $U_{H L}<U_{L L}=x_{L}+\lambda\left(a_{1}(1-\theta)+a_{2} \theta\right)$. Note that since the lowest possible 
type is $a_{1}, U_{H L} \geq x_{L}+\lambda a_{1}$. We use the off-equilibrium belief that $U_{H L}=x_{L}+\lambda a_{1}$ to construct conditions that would support this equilibrium: $\left(x_{H}-x_{L}+\lambda\left(a_{3}-a_{2}\right)\right) \frac{\delta p_{L}}{(1-\theta) p_{H}+\delta p_{L}}+$ $\lambda\left(a_{2}-a_{1}\right) \frac{\delta p_{L}(1-\theta)}{(1-\theta) p_{H}+\delta p_{L}}<\frac{\left(1-p_{H h}\right)(1-\delta)}{1-\left(1-p_{H h}\right)(1-\delta)} \theta \lambda\left(a_{2}-a_{1}\right)$

However any off-equilibrium belief that satisfies $U_{H L}<U_{L L}=x_{L}+\lambda\left(a_{1}(1-\theta)+a_{2} \theta\right)$ also renders this equilibrium being eliminated by the intuitive criterion. To see this, note that the offequilibrium message $\left\{D_{H}, R_{L}\right\}$ can only be possibly sent by manager of type $\sigma=0$, or $s=h$, or $s=l$. Condition (A1) indicates that manager of type $s=h$ or $s=l$ has no incentive to deviate to $D_{H}$, thus this message, if observed, must come from manager of type $\sigma=0$. This means $E\left[a \mid D_{H}, R_{L}\right]=a_{2}>a_{1}(1-\theta)+a_{2} \theta$ and $U_{H L}=x_{L}+\lambda a_{2}>U_{L L}$. We thus conclude that this equilibrium can be eliminated by the intuitive criterion.

Case 3: Manager of type $\sigma=0$ or $s=l$ discloses $D_{L}$ and does not engage in earnings management. Manager of type $\sigma=1$ or $s=h$ discloses $D_{H}$ and manages earnings upward when $x=x_{L}$ but not downward when $x=x_{H}$.

Note this case requires $U_{L L}>U_{L H}$. However, given the conjectured strategy, $U_{L L}=x_{L}+$ $E\left[a \mid D_{L}, R_{L}\right]$ whereas $U_{L H}=x_{H}+a_{3}>U_{L L}$. Thus, the conjectured strategy cannot be an equilibrium strategy.

Case 4: Manager of type $\sigma=0$ or $s=l$ discloses $D_{L}$ and manages earnings upward when $x=$ $x_{L}$ but not downward when $x=x_{H}$. Manager of type $\sigma=1$ or $s=h$ discloses $D_{H}$ and does not engage in upward earnings management.

For this conjectured strategy to be sustained in equilibrium, we need $U_{H H}>U_{H L}$ so that manager of type $\sigma=1$ will not manage earnings downward. But then manager of type $s=h$ 
will have an incentive to manage earnings upward because $\left(1-\left(1-p_{H h}\right)(1-\delta)\right) U_{H H}+$ $\left(1-p_{H h}\right)(1-\delta) U_{H L}>p_{H h} U_{H H}+\left(1-p_{H h}\right) U_{H L}$. Thus, the conjectured strategy cannot be an equilibrium strategy.

Case 5: Manager of type $\sigma=0$ or $s=l$ discloses $D_{L}$ and manages earnings upward when $x=$ $x_{L}$ but not downward when $x=x_{H}$. Manager of type $\sigma=1$ or $s=h$ discloses $D_{H}$ and manages earnings upward when $x=x_{L}$ but not downward when $x=x_{H}$. Since all manager types manage earnings upward when $x=x_{L}, E\left[\tilde{x} \mid D_{t}, R_{L}\right]=x_{L}$ for $t=L, H$.

Based on the manager's strategy, $\left\{D_{H}, R_{L}\right\}$ can only occur for manager of type $a_{1}$. Thus $E\left[a \mid D_{H}, R_{L}\right]=a_{1}$, and, $U_{H L}=E\left[\tilde{x}+\lambda a \mid D_{H}, R_{L}\right]=x_{L}+\lambda a_{1}$. Further, $\left\{D_{L}, R_{L}\right\}$ can only occur for manager of type $a_{1}$ or $a_{2}$. Thus, $E\left[a \mid D_{L}, R_{L}\right]=a_{1} p\left(a_{1} \mid D_{L}, R_{L}\right)+a_{2} p\left(a_{2} \mid D_{L}, R_{L}\right)$. By Bayes' Rule, $\left(a_{1} \mid D_{L}, R_{L}\right)=\frac{p\left(D_{L}, R_{L} \mid a_{1}\right) p\left(a_{1}\right)}{p\left(D_{L}, R_{L} \mid a_{1}\right) p\left(a_{1}\right)+p\left(D_{L}, R_{L} \mid a_{2}\right) p\left(a_{2}\right)}=\frac{(1-\delta) q p_{L}(1-\theta)}{(1-\delta) q p_{L}(1-\theta)+(1-\delta) p_{L} \theta}=$ $\frac{q(1-\theta)}{q(1-\theta)+\theta}$. Thus we have: $E\left[a \mid D_{L}, R_{L}\right]=a_{1} \frac{q(1-\theta)}{q(1-\theta)+\theta}+a_{2} \frac{\theta}{q(1-\theta)+\theta}$, and, $U_{L L}=$ $E\left[\tilde{x}+\lambda a \mid D_{L}, R_{L}\right]=x_{L}+\lambda\left(a_{1} \frac{q(1-\theta)}{q(1-\theta)+\theta}+a_{2} \frac{\theta}{q(1-\theta)+\theta}\right)$.

Similarly, $U_{L H} \equiv E\left[\tilde{x}+\lambda a \mid D_{L}, R_{H}\right]=x_{H} \frac{(1-q)(1-\theta) p_{H}}{(1-q)(1-\theta) p_{H}+\delta(\theta+(1-\theta) q) p_{L}}+$ $x_{L} \frac{\delta(\theta+(1-\theta) q) p_{L}}{(1-q)(1-\theta) p_{H}+\delta(\theta+(1-\theta) q) p_{L}}+\quad \lambda a_{1} \frac{q \delta p_{L}(1-\theta)}{q \delta p_{L}(1-\theta)+\delta p_{L} \theta+(1-q) p_{H}(1-\theta)}+$ $\lambda a_{2} \frac{\delta p_{L} \theta}{q \delta p_{L}(1-\theta)+\delta p_{L} \theta+(1-q) p_{H}(1-\theta)}+\quad \lambda a_{3} \frac{(1-q) p_{H}(1-\theta)}{q \delta p_{L}(1-\theta)+\delta p_{L} \theta+(1-q) p_{H}(1-\theta)}$, and, $U_{H H} \equiv E\left[\tilde{x}+\lambda a \mid D_{H}, R_{H}\right]=\quad x_{H} \frac{(1-(1-q)(1-\theta)) p_{H}}{(1-(1-q)(1-\theta)) p_{H}+\delta(1-\theta)(1-q) p_{L}}+$ $x_{L} \frac{\delta(1-\theta)(1-q) p_{L}}{(1-(1-q)(1-\theta)) p_{H}+\delta(1-\theta)(1-q) p_{L}}+\quad \lambda a_{1} \frac{(1-q) \delta p_{L}(1-\theta)}{(1-q) \delta p_{L}(1-\theta)+q p_{H}(1-\theta)+p_{H} \theta}+$ $\lambda a_{3} \frac{q p_{H}(1-\theta)+p_{H} \theta}{(1-q) \delta p_{L}(1-\theta)+q p_{H}(1-\theta)+p_{H} \theta}$. 
In order for this equilibrium to be sustainable, to the following conditions must be satisfied:

$\frac{\left(1-p_{H h}\right)(1-\delta)}{1-\left(1-p_{H h}\right)(1-\delta)}\left(U_{L L}-U_{H L}\right)<U_{H H}-U_{L H}<\frac{\left(1-p_{H l}\right)(1-\delta)}{1-\left(1-p_{H l}\right)(1-\delta)}\left(U_{L L}-U_{H L}\right)$.

Inserting the expressions of $U_{H H}, U_{H L}, U_{L H}$ and $U_{L L}, p_{H h}$ and $p_{H l}$ into (A2), we have:

$$
\begin{aligned}
& \lambda\left(a_{2}-a_{1}\right) \frac{(1-\delta) p_{L}(1-q)}{\delta p_{L}(1-q)+p_{H} q} \frac{\theta}{q(1-\theta)+\theta}< \\
& \left(x_{H}-x_{L}+\lambda\left(a_{3}-a_{2}\right)\right) \frac{\delta p_{L} p_{H}(2 q-1+2 \theta(1-q))}{\left(p_{H}(q+\theta)-p_{H} q \theta+\delta p_{L}(1-q)(1-\theta)\right)\left((1-q)(1-\theta) p_{H}+\delta p_{L}(q+\theta-q \theta)\right)} \\
& +\lambda\left(a_{2}-a_{1}\right) \frac{\delta p_{L}(1-\theta)\left(-\delta p_{L}(1-q) \theta+p_{H}(q(2-\theta)-(1-\theta))\right)}{\left(p_{H}(q+\theta)-p_{H} q \theta+\delta p_{L}(1-q)(1-\theta)\right)\left((1-q)(1-\theta) p_{H}+\delta p_{L}(q+\theta-q \theta)\right)} \\
& <\lambda\left(a_{2}-a_{1}\right) \frac{(1-\delta) p_{L} q}{\delta p_{L} q+p_{H}(1-q)} \frac{\theta}{q(1-\theta)+\theta} .
\end{aligned}
$$

We denote this equilibrium as "separation with management equilibrium" since in this equilibrium, $D_{L}$ and $D_{H}$ convey relatively bad and good news respectively.

Case 6: Manager of type $\sigma=0$ discloses $D_{L}$ and manages earnings upward. All other manager types disclose $D_{H}$ and do not manage earnings upward.

This conjectured strategy cannot be sustained in equilibrium as it requires $U_{H H}>U_{H L}$ so that manager of type $\sigma=1$ has no incentive to manage earnings downward. However, this gives manager of type $s=h$ or $s=l$ incentive to manage earnings upward.

Case 7: Manager of type $\sigma=0$ discloses and discloses $D_{L}$ and manages earnings upward. All other manager types disclose $D_{H}$ and manages earnings upward when $x=x_{L}$ but not downward when $x=x_{H}$. This conjectured equilibrium strategy profile results in the following payoffs to the manager: 
$U_{H L}=x_{L}+\lambda a_{1} ; U_{L L}=x_{L}+\lambda a_{2} ; U_{L H}=x_{L}+\lambda a_{2} ;$ and, $U_{H H}=x_{H} \frac{p_{H}}{p_{H}+\delta(1-\theta) p_{L}}+$

$x_{L} \frac{\delta(1-\theta) p_{L}}{p_{H}+\delta(1-\theta) p_{L}}+\lambda\left(a_{1} \frac{\delta p_{L}(1-\theta)}{\delta p_{L}(1-\theta)+p_{H}}+a_{3} \frac{p_{H}}{\delta p_{L}(1-\theta)+p_{H}}\right)$.

For this conjectured strategy to be sustained in equilibrium, the following conditions must be satisfied: $\frac{\left(1-p_{H l}\right)(1-\delta)}{1-\left(1-p_{H l}\right)(1-\delta)}\left(U_{L L}-U_{H L}\right)<U_{H H}-U_{L H}<\frac{1-\delta}{\delta}\left(U_{L L}-U_{H L}\right)$, or, equivalently,

$\frac{\left(1-p_{H l}\right)(1-\delta)}{1-\left(1-p_{H l}\right)(1-\delta)} \lambda\left(a_{2}-a_{1}\right)<\left(x_{H}-x_{L}-\lambda\left(a_{2}-a_{1}\right)\right) \frac{\delta p_{L}(1-\theta)}{\delta p_{L}(1-\theta)+p_{H}}+\lambda\left(a_{3}-a_{2}\right) \frac{p_{H}}{\delta p_{L}(1-\theta)+p_{H}}<$ $\frac{1-\delta}{\delta} \lambda\left(a_{2}-a_{1}\right)$

We denote this equilibrium as "reverse sanitization with management equilibrium" since in this equilibrium, the manager discloses the upper bound of his private information, which is exactly opposite to his disclosure strategy in the "sanitization with management equilibrium".

This equilibrium, however, fails the criterion of invariance to deletion of redundant strategies proposed in Govindan and Wilson (2006). Since $U_{L L}=U_{L H}$, managing earnings upward when $x=x_{L}$ for manager of type $\sigma=0$ is a redundant strategy. Eliminating this strategy results in $\left\{D_{L}, R_{H}\right\}$ being off-equilibrium. The manager of type $\sigma=1$ will then have an incentive to deviate and send the off-equilibrium message $D_{L}$ since $U_{L H}=E\left[\tilde{x}+\lambda a \mid D_{L}, R_{H}\right]=x_{H}+$ $\lambda a_{3}>U_{H H}$

To summarize, in addition to the "uninformative equilibrium", under certain conditions, we have possibly the following three pure strategy informative equilibria. 
1. a "sanitization with management equilibrium" where the manager discloses $D_{H}$ when observing $\sigma=1$ and discloses $D_{L}$ otherwise, and manages earnings up for

$$
\begin{aligned}
& x=x_{L}, \text { if }\left(x_{H}-x_{L}+\lambda\left(a_{3}-a_{2}\right)\right) \frac{\delta p_{L}}{(1-\theta) p_{H}+p p_{L}}+\lambda\left(a_{2}-a_{1}\right) \frac{\delta p_{L}(1-\theta)}{(1-\theta) p_{H}+\delta p_{L}} \\
& <\lambda\left(a_{2}-a_{1}\right) \frac{(1-\delta)\left(1-p_{H}\right)(1-q)}{\delta\left(1-p_{H}\right)(1-q)+p_{H} q} \theta ;
\end{aligned}
$$

2. a "separation with management equilibrium" where the manager discloses $D_{H}$ when observing $\sigma=1$ or $s=h$, and discloses $D_{L}$ otherwise, and manages earnings up

$$
\begin{aligned}
& \text { for } x=x_{L}, \text { if } \lambda\left(a_{2}-a_{1}\right) \frac{(1-\delta)\left(1-p_{H}\right)(1-q)}{\delta\left(1-p_{H}\right)(1-q)+p_{H} q} \frac{\theta}{q(1-\theta)+\theta}< \\
& \left(x_{H}-x_{L}+\lambda\left(a_{3}-a_{2}\right)\right) \times \frac{\delta p_{L} p_{H}(2 q-1+2 \theta(1-q))}{\left(p_{H}(q+\theta)-p_{H} q \theta+\delta p_{L}(1-q)(1-\theta)\right)\left((1-q)(1-\theta) p_{H}+\delta p_{L}(q+\theta-q \theta)\right)} \\
& +\lambda\left(a_{2}-a_{1}\right) \times \frac{\delta p_{L}(1-\theta)\left(-\delta p_{L}(1-q) \theta+p_{H}(q(2-\theta)-(1-\theta))\right)}{\left(p_{H}(q+\theta)-p_{H} q \theta+\delta p_{L}(1-q)(1-\theta)\right)\left((1-q)(1-\theta) p_{H}+\delta p_{L}(q+\theta-q \theta)\right)} \\
& <\lambda\left(a_{2}-a_{1}\right) \frac{(1-\delta)\left(1-p_{H}\right) q}{\delta\left(1-p_{H}\right) q+p_{H}(1-q)} \frac{\theta}{q(1-\theta)+\theta} ; \text { and finally, }
\end{aligned}
$$

3. a "reverse sanitization with management equilibrium" where the manager discloses $D_{L}$ when observing $\sigma=0$, and discloses $D_{H}$ otherwise, and manages earnings up

$$
\begin{aligned}
& \text { for } x=x_{L}, \text { if } \quad \lambda\left(a_{2}-a_{1}\right) \frac{(1-\delta)\left(1-p_{H}\right) q}{\delta\left(1-p_{H}\right) q+p_{H}(1-q)}<\left(x_{H}-x_{L}+\lambda\left(a_{3}-\right.\right. \\
& \left.\left.a_{2}\right)\right) \frac{p_{H}}{\delta p_{L}(1-\theta)+p_{H}}-\lambda\left(a_{2}-a_{1}\right) \frac{\delta p_{L}(1-\theta)}{\delta p_{L}(1-\theta)+p_{H}}<\frac{1-\delta}{\delta} \lambda\left(a_{2}-a_{1}\right) .
\end{aligned}
$$

Among these three pure strategy equilibria, equilibria 1) and 3) can be eliminated using proper equilibrium selection criteria.

Next we derive the conditions for the existence of these three equilibria. Denote

$$
\frac{x_{H}-x_{L}+\lambda\left(a_{3}-a_{2}\right)}{\lambda\left(a_{2}-a_{1}\right)}=k>0 .
$$


For the "sanitization with management equilibrium," the condition to sustain this equilibrium can be rewritten $\operatorname{as}(k+1-\theta) \frac{\delta p_{L}}{(1-\theta) p_{H}+\delta p_{L}}<\frac{(1-\delta) p_{L}(1-q)}{\delta p_{L}(1-q)+p_{H} q} \theta$.

The left hand side (LHS) of (A3) increases in $\delta$ and the right hand side (RHS) of (A3)

decreases in $\delta$. When $\delta \rightarrow 0$, the LHS approaches zero, which is smaller than the RHS.

Similarly, when $\delta \rightarrow 1$, the RHS approaches zero, which is smaller than the LHS.

Therefore, there exists a $\delta_{s m}^{*} \in(0,1)$ s.t. the "sanitization with management" equilibrium is sustainable when $\delta<\delta_{s m}^{*}$

For the "reverse sanitization with management equilibrium," the equilibrium conditions can be rewritten as $\frac{\left(1-p_{H l}\right)(1-\delta)}{1-\left(1-p_{H l}\right)(1-\delta)}<k \frac{p_{H}}{\delta p_{L}(1-\theta)+p_{H}}-\frac{\delta p_{L}(1-\theta)}{\delta p_{L}(1-\theta)+p_{H}}<\frac{1-\delta}{\delta}$, which is equivalent to $\frac{1}{1-\left(1-p_{H l}\right)(1-\delta)}<(k+1) \frac{p_{H}}{\delta p_{L}(1-\theta)+p_{H}}<\frac{1}{\delta}$. We can further write the above condition as $\frac{p_{H}(1-q)}{p_{H}(1-q)+q\left(1-p_{H}\right)}+\frac{q\left(1-p_{H}\right)}{p_{H}(1-q)+q\left(1-p_{H}\right)} \delta>\frac{\delta p_{L}(1-\theta)}{p_{H}(k+1)}+\frac{1}{k+1}>\delta$.

Since the above two equilibria can be eliminated, we focus on the "separation with management equilibrium." We rewrite the equilibrium condition as

$$
\begin{aligned}
& A_{1}(\delta) \equiv \frac{(1-\delta)\left(1-p_{H}\right)(1-q)}{\delta\left(1-p_{H}\right)(1-q)+p_{H} q} \frac{\theta}{q(1-\theta)+\theta}< \\
& k \frac{\delta p_{L} p_{H}(2 q-1+2 \theta(1-q))}{\left(p_{H}(q+\theta)-p_{H} q \theta+\delta p_{L}(1-q)(1-\theta)\right)\left((1-q)(1-\theta) p_{H}+\delta p_{L}(q+\theta-q \theta)\right)} \\
& +\frac{\delta p_{L}(1-\theta)\left(-\delta p_{L}(1-q) \theta+p_{H}(q(2-\theta)-(1-\theta))\right)}{\left(p_{H}(q+\theta)-p_{H} q \theta+\delta p_{L}(1-q)(1-\theta)\right)\left((1-q)(1-\theta) p_{H}+\delta p_{L}(q+\theta-q \theta)\right)} \equiv A_{2}(\delta) \\
& <\frac{(1-\delta)\left(1-p_{H}\right) q}{\delta\left(1-p_{H}\right) q+p_{H}(1-q)} \frac{\theta}{q(1-\theta)+\theta} \equiv A_{3}(\delta)
\end{aligned}
$$


It can be verified that when $\delta=0, A_{2}(0)=0<A_{1}(0)$ and $A_{2}(0)=0<A_{3}(0)$; when $\delta=1$ and $p_{H}>\frac{\theta(1-q)}{\theta+(1-\theta)(2 q-1)}\left(\right.$ i.e., $\left.-\delta p_{L}(1-q) \theta+p_{H}(q(2-\theta)-(1-\theta))>0\right), A_{2}(1)>0=$ $A_{1}(1)$ and $A_{2}(1)>0=A_{3}(1)$. Note that $q>\frac{1}{2}$ implies $p_{H} q^{2}>p_{H}(1-q)^{2}$, which in turn implies that $\frac{(1-\delta)\left(1-p_{H}\right)(1-q)}{\delta\left(1-p_{H}\right)(1-q)+p_{H} q}<\frac{(1-\delta)\left(1-p_{H}\right) q}{\delta\left(1-p_{H}\right) q+p_{H}(1-q)}$ for any $\delta \in[0,1)$. This means

$A_{3}(\delta)>A_{1}(\delta)$ for any $\delta \in[0,1)$. By continuity, there must exist some $\delta^{*} \in(0,1)$ such that $A_{1}\left(\delta^{*}\right)<A_{2}\left(\delta^{*}\right)<A_{3}\left(\delta^{*}\right)$. This proves part i).

Further: (1) $A_{1}(\delta)$ and $A_{3}(\delta)$ decrease in $\delta$, and $A_{2}(\delta)$ increases in $\delta$ when $k$ is sufficiently large and $\frac{p_{H}}{1-p_{H}} \geq \frac{1}{2}-$ this can be shown since the first term in $A_{2}(\delta)$, i.e., $\frac{\delta p_{L} p_{H}(2 q-1+2 \theta(1-q))}{\left(p_{H}(q+\theta)-p_{H} q \theta+\delta p_{L}(1-q)(1-\theta)\right)\left((1-q)(1-\theta) p_{H}+\delta p_{L}(q+\theta-q \theta)\right)}$ is increasing in $\delta$ when $\delta<\frac{p_{H}^{2}}{\left(1-p_{H}\right)^{2}}$, which is automatically satisfied when $p_{H} \geq \frac{1}{2}$; (2) $A_{1}(\delta)<A_{3}(\delta) \forall \delta$; (3) when $\delta=0$, $A_{2}(\delta)<A_{1}(\delta)$ and $A_{2}(\delta)<A_{3}(\delta)$; and (4) when $\delta=1, A_{2}(\delta)>0=A_{1}(\delta)$ and $A_{2}(\delta)>0=A_{3}(\delta)$. By continuity there must exist some $\underline{\delta}, \bar{\delta} \in(0,1)$ and $\underline{\delta}<\bar{\delta}$ such that $A_{1}(\underline{\delta})=A_{2}(\underline{\delta})$ and $A_{2}(\bar{\delta})=A_{3}(\bar{\delta})$. This implies that $A_{1}(\delta)<A_{2}(\delta)<A_{3}(\delta)$ for $\delta \in(\underline{\delta}, \bar{\delta})$. This proves part ii).

To prove part iii), note that when $p_{H}=0, A_{1}(\delta)=A_{3}(\delta)>0=A_{2}(\delta)$. Thus (A4) is violated. By continuity this equilibrium does not exist when $p_{H}$ is sufficiently small. Q.E.D.

\section{Proof of Proposition 3:}

The (inverse of) price informativeness metric can be written as:

$$
E\left((P(D)-x)^{2}\right)=\sum_{i} \sum_{j} p_{i} p\left(D_{j} \mid x_{i}\right)\left\{P\left(D_{j} \mid x_{i}\right)-x_{i}\right\}^{2} \text { for } i, j=L, H
$$


First we examine the "sanitization equilibrium" characterized in Proposition 1, which is the most informative equilibrium when no reporting discretion is allowed.

We first derive the expressions for $P\left(D_{L}\right)$ and $P\left(D_{H}\right)$.

Based on the sanitization strategy, $D_{H}$ is perfectly informative that $x=x_{H}$. Thus $P\left(D_{H}\right)=x_{H}$.

To calculate $P\left(D_{L}\right)$, we need to calculate $p\left(x_{H} \mid D_{L}\right)$. By Bayes' Rule, we have

$p\left(x_{H} \mid D_{L}\right)=\frac{p\left(D_{L} \mid x_{H}\right) p_{H}}{p\left(D_{L} \mid x_{H}\right) p_{H}+p\left(D_{L} \mid x_{L}\right) p_{L}}=\frac{(1-\theta) p_{H}}{(1-\theta) p_{H}+p_{L}}$, and thus, $P\left(D_{L}\right)=x_{H} \frac{(1-\theta) p_{H}}{(1-\theta) p_{H}+p_{L}}+$

$x_{L} \frac{p_{L}}{(1-\theta) p_{H}+p_{L}}$.

Inserting the expressions of $P\left(D_{H}\right)$ and $P\left(D_{L}\right)$ into the expression of $E\left((P(D)-x)^{2}\right)$, we have

$E^{n}\left((P(D)-x)^{2}\right)=p_{H}(1-\theta)\left(x_{H}-P\left(D_{L}\right)\right)^{2}+p_{L}\left(x_{L}-P\left(D_{L}\right)\right)^{2}=\frac{p_{H} p_{L}(1-\theta)}{(1-\theta) p_{H}+p_{L}}\left(x_{H}-x_{L}\right)^{2}$,

where the superscript $n$ refers to "no discretion allowed".

Similarly, for the "separation with management equilibrium" characterized in Proposition 2,

$P\left(D_{H}\right)=x_{H} \frac{(\theta+(1-\theta) q) p_{H}}{(\theta+(1-\theta) q) p_{H}+(1-\theta)(1-q) p_{L}}+x_{L} \frac{(1-\theta)(1-q) p_{L}}{(\theta+(1-\theta) q) p_{H}+(1-\theta)(1-q) p_{L}}$, and,

$P\left(D_{L}\right)=x_{H} \frac{(1-\theta)(1-q) p_{H}}{(1-\theta)(1-q) p_{H}+(\theta+(1-\theta) q) p_{L}}+x_{L} \frac{(\theta+(1-\theta) q) p_{L}}{(1-\theta)(1-q) p_{H}+(\theta+(1-\theta) q) p_{L}}$.

Inserting the expressions of $P\left(D_{H}\right)$ and $P\left(D_{L}\right)$ into the expression of $E\left((P(D)-x)^{2}\right)$, we have:

$$
\begin{aligned}
& E^{d}\left((P(D)-x)^{2}\right)=\left(p_{H} \theta+p_{H}(1-\theta) q\right)\left(x_{H}-P\left(D_{H}\right)\right)^{2}+p_{H}(1-\theta)(1-q)\left(x_{H}-P\left(D_{L}\right)\right)^{2} \\
& +\left(p_{L} \theta+p_{L}(1-\theta) q\right)\left(x_{L}-P\left(D_{L}\right)\right)^{2}+p_{L}(1-\theta)(1-q)\left(x_{L}-P\left(D_{H}\right)\right)^{2}
\end{aligned}
$$


$=\frac{p_{H} p_{L}(1-\theta)(1-q)(\theta+(1-\theta) q)}{\left((\theta+(1-\theta) q) p_{H}+(1-\theta)(1-q) p_{L}\right)\left((1-\theta)(1-q) p_{H}+(\theta+(1-\theta) q) p_{L}\right)}\left(x_{H}-x_{L}\right)^{2}$.

Denote $t=(1-\theta)(1-q)<\frac{1}{2}(1-\theta)$, we can then write $E^{d}\left((P(D)-x)^{2}\right)$ as

$E^{d}\left((P(D)-x)^{2}\right)=p_{H} p_{L}\left(x_{H}-x_{L}\right)^{2} f(t)$ where $f(t)=\frac{t(1-t)}{\left(t+(1-2 t) p_{H}\right)\left(1-t-(1-2 t) p_{H}\right)}$. It can be shown that $f^{\prime}(t)=\frac{p_{H}\left(1-p_{H}\right)(1-2 t)}{\left(t+(1-2 t) p_{H}\right)^{2}\left(1-t-(1-2 t) p_{H}\right)^{2}}>0$. Thus $E^{d}\left((P(D)-x)^{2}\right)$ is increasing in $t$ and decreasing in $q$.

When $q \rightarrow 1, t \rightarrow 0, E^{d}\left((P(D)-x)^{2}\right) \rightarrow 0<E^{n}\left((P(D)-x)^{2}\right)$;

When $q \rightarrow \frac{1}{2}, t \rightarrow \frac{1}{2}(1-\theta), E^{d}\left((P(D)-x)^{2}\right) \rightarrow p_{H} p_{L}\left(x_{H}-x_{L}\right)^{2} \frac{(1-\theta)(1+\theta)}{1-\left(2 p_{H}-1\right)^{2} \theta^{2}}$.

Thus, when $q \rightarrow \frac{1}{2}, E^{d}\left((P(D)-x)^{2}\right) \leq E^{n}\left((P(D)-x)^{2}\right)$ if and only if $\frac{(1+\theta)}{1-\left(2 p_{H^{-}}-1\right)^{2} \theta^{2}} \leq$ $\frac{1}{(1-\theta) p_{H}+p_{L}}=\frac{1}{1-\theta p_{H}}$, i.e., $p_{H} \geq \frac{1+\theta}{4 \theta}$.

Therefore, when $p_{H} \geq \frac{1+\theta}{4 \theta}$, voluntary disclosure with discretion in subsequent mandatory disclosure is always more informative than the sanitization voluntary disclosure without that discretion. When $p_{H}<\frac{1+\theta}{4 \theta}$, there exists a $q^{*} \in\left(\frac{1}{2}, 1\right)$ s.t. voluntary disclosure with discretion in subsequent mandatory disclosure is more informative than the sanitization voluntary disclosure without that discretion when $q>q^{*}$ with $q^{*}=1-\frac{t^{*}}{1-\theta}$ being defined by the unique solution $t^{*}$ to the following equation: $\frac{t^{*}\left(1-t^{*}\right)}{\left(t^{*}+\left(1-2 t^{*}\right) p_{H}\right)\left(1-t^{*}-\left(1-2 t^{*}\right) p_{H}\right)}=\frac{1-\theta}{(1-\theta) p_{H}+p_{L}}$. Q.E.D. 